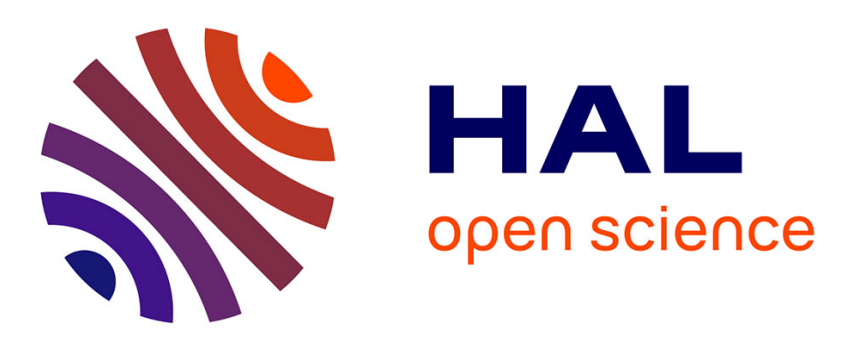

\title{
Intrinsic hydrophobicity of smectite basal surfaces quantitatively probed by molecular dynamics simulations
}

\author{
Marek Szczerba, Andrey G. Kalinichev, Mariola Kowalik
}

\section{To cite this version:}

Marek Szczerba, Andrey G. Kalinichev, Mariola Kowalik. Intrinsic hydrophobicity of smectite basal surfaces quantitatively probed by molecular dynamics simulations. Appl.Clay Sc., 2020, 188, pp.105497. 10.1016/j.clay.2020.105497 . hal-02542868

\section{HAL Id: hal-02542868 \\ https://hal.science/hal-02542868}

Submitted on 15 Feb 2022

HAL is a multi-disciplinary open access archive for the deposit and dissemination of scientific research documents, whether they are published or not. The documents may come from teaching and research institutions in France or abroad, or from public or private research centers.
L'archive ouverte pluridisciplinaire HAL, est destinée au dépôt et à la diffusion de documents scientifiques de niveau recherche, publiés ou non, émanant des établissements d'enseignement et de recherche français ou étrangers, des laboratoires publics ou privés. 
1 Intrinsic hydrophobicity of smectite basal surfaces quantitatively probed by molecular

2

3

4

5

6

\section{dynamics simulations}

Marek Szczerba ${ }^{1, *}$, Andrey G. Kalinichev ${ }^{2,3}$, Mariola Kowalik ${ }^{1}$

${ }^{1}$ Institute of Geological Sciences, Polish Academy of Sciences, Krakow, Poland

${ }^{2}$ Laboratoire SUBATECH (UMR 6457 - Institut Mines-Télécom Atlantique, Université de Nantes, CNRS/IN2P3) Nantes, France

${ }^{3}$ National Research University Higher School of Economics, Moscow, Russian Federation

*Corresponding author: Marek Szczerba (ndszczer@cyf-kr.edu.pl)

KEY WORDS: clay-water interface, hydrophobicity, adsorbed water, smectite, molecular dynamics simulations 


\section{ABSTRACT}

The siloxane surface of uncharged clays is known to be hydrophobic, which is supported by strong experimental and theoretical evidence. For the siloxane surface of charged clays, like smectites, the picture is not as clear. We are aiming to clarify this issue by molecular simulations in which smectite surface hydrophobicity is quantified through the separate contribution of the surface itself, and the contribution due to the presence of chargebalancing cations on the surface. In order to explore systematically the effects of the total smectite charge and its distribution in the structure, a series of molecular dynamics (MD) simulations was performed for several models of dioctahedral smectites and compared with the results for uncharged pyrophyllite.

The largest difference between the simulation results for smectite models with naturally present surface counterions and the models where these ions were artificially removed from the surface, while maintaining the same total charge balance of the model, is in the shape of the water coverage. In the former case, full surface wetting is observed and a relatively flat water film is forming on the surface. Its irregularity and thickness is connected with number of ions on the surface. However, in all cases of smectite surfaces artificially devoid of ions, a water droplet is always formed and the wetting is incomplete. The contact angles of the water droplets on charged montmorillonites are very similar to that on uncharged pyrophyllite surface and range roughly between $110^{\circ}$ and $90^{\circ}$. These angles are also affected by the distribution of the octahedral and tetrahedral substitutions in the structure and by their ratio. In the case of purely tetrahedral substitutions the contact angle on the bare smectite surface can be as low as $\sim 60^{\circ}$, but still far from complete wetting.

The angular distributions of the $\mathrm{H}_{2} \mathrm{O}$ dipole vectors as a function of distance from the smectite surface show two preferred surface-oriented types of water molecules when counterions are present, and the total surface is highly hydrophilic. However, for surfaces 
47 devoid of ions, a population with dipole angles close to $\sim 90^{\circ}$ is dominating, and the smectite surfaces can be considered hydrophobic. It can be thus concluded that, independent of the structural charge, bare smectite surfaces by themselves are either hydrophobic or only moderately hydrophilic. Their experimentally observed highly hydrophilic character is almost entirely due to the charge balancing cations present on the surface. 


\section{INTRODUCTION}

Hydrophobicity of a surface is manifested by repelling water molecules. In practice, this is due to the surface attractive forces towards $\mathrm{H}_{2} \mathrm{O}$ molecules being much weaker than the attractive forces between $\mathrm{H}_{2} \mathrm{O}$ molecules themselves. Therefore, water forms a droplet on such a surface. Generally, if the surface is hydrophobic, it has higher affinity towards oil phase. This effect plays crucial role in the case of clay minerals, as these are major constituents of rock formations associated with natural hydrocarbon reservoirs. A large number of recent molecular simulation studies have demonstrated and confirmed that affinity of aluminosilicate surfaces to hydrophilic or hydrophobic molecules strongly affects their sorption (e.g., Tenney and Cygan, 2014; Smirnov, 2017a; Myshakin and Cygan, 2018; Greathouse et al., 2018; Liu et al., 2019; Willemsen et al., 2019).

Clay minerals can possess neutral layer charge or have a net negative structural charge that is balanced by the interlayer and/or surface cations. There is a strong experimental and theoretical evidence of hydrophobic character of the siloxane surface of uncharged clays (e.g., Bridgeman and Skipper, 1997; Arab et al., 2003; Tunega et al., 2004; Churakov, 2006; Šolc et al., 2011). In the case of trioctahedral structures (talc), the degree of hydrophobicity can vary depending on the relative humidity (Michot et al., 1994; Rotenberg et al., 2011) or external pressure on the system (Wang et al., 2004; 2005a). Thermal treatment $\left(>900{ }^{\circ} \mathrm{C}\right)$ can also significantly affect the hydrophobicity of talc, due to the disordering of silica tetrahedron structures and formation of amorphous silica phases (Yi et al., 2019).

For siloxane surfaces of charged clays, like smectites, the picture is not as clear. Based on aromatic hydrocarbon adsorption experiments, Jaynes and Boyd (1991) have classified the smectite surface as mostly hydrophobic. Relative weakness of the hydrogen bonds donated by the interlayer $\mathrm{H}_{2} \mathrm{O}$ molecules to the clay basal surface, compared to a typical strength of $\mathrm{H}_{2} \mathrm{O}$ $\mathrm{H}_{2} \mathrm{O}$ bonds in bulk liquid water can be considered as molecular-scale indication of the relative 
hydrophobicity of smectite siloxane surfaces (Kuligiewicz et al., 2015; Szczerba et al., 2016). On the other hand, Sobolev et al. (2010) have used neutron scattering technique to determine that the surfaces of smectite clays with tetrahedral substitutions are hydrophilic. The importance of specific location of the structural charge within the clay layer for the existence of hydrophobic and hydrophilic patches on the surfaces of clay particles has also been confirmed in earlier Monte Carlo computer simulations (Sposito et al., 1999).

Important properties related to the surface hydrophobicity of 2:1 clay minerals are the surface energy and the total structural charge of the clay layer (Liu et al., 2007; Shen et al., 2017; Hartkamp et al., 2018). To measure the charge of the layers, a new O-D method, employing IR spectroscopic measurements, has been recently developed (Kuligiewicz et al., 2015; Kuligiewicz et al., 2018). Edge hydroxyl groups can be distinguished from $\mathrm{H}_{2} \mathrm{O}$ molecules at basal surfaces after deuteration also by means of vibrational spectroscopy (Harvey et al., 2019). Studies on electroosmotic flow through hydrophobic nanochannels have shown the dependence of the flow on the surface charge density (Silkina et al., 2019).

Wettability of minerals can be directly related to hydrophobicity. It has been shown that introduction of anions or cations on the smectite surface plays a key role in adsorption of water molecules by these minerals (Dazas et al., 2013; Dazas et al., 2015; Zhang et al., 2016; Zhou et al., 2019). Attention should be also paid to the topography of the smectite surface, which can significantly affect the surface wettability (Ou et al., 2018; Xi et al., 2017). It should be also noted that a smectite surface can be defined in two different ways: as bare siloxane surface of the crystal or as a surface covered with charge balancing cations. Wettability can be more directly discussed using the second definition of the surface. On the other hand, it seems more appropriate to use the first definition for the analysis of the balance of hydrogen bonding $\mathrm{H}_{2} \mathrm{O}$-surface and $\mathrm{H}_{2} \mathrm{O}-\mathrm{H}_{2} \mathrm{O}$. 
shown different nature of tetrahedral (siloxane surface) and octahedral (hydroxylated) sheets, that are hydrophobic and hydrophilic, respectively (Tunega et al., 2002). Skeletal aluminosilicates, i.e. zeolites, have an affinity for hydrophobic molecules, although the hydroxyl groups on the outer surface act as hydrophilic adsorption sites (Smirnov, 2017b).

The present study aims to develop these considerations further by adding new quantitative arguments based on a specially designed series of molecular simulations. Theoretical calculations offer the unique ability to separate the effects of various compositional and structural features of model systems on the observed properties, and this methodology is employed here to quantitatively evaluate the hydrophobicity of smectite surfaces from which all charge balancing cations have been removed.

There are various methods for assessing surface hydrophobicity based on molecular simulations. For example, one can calculate the potential of mean force for the transfer of a water molecule from the bulk liquid phase to the surface or from the gas phase to the surface. Another method, more directly comparable with experimental observations, is the calculation of the contact angle a water nanodroplet can form on the surface (Giovambattista et al., 2007; Zheng and Zaoui, 2016; Khalkhall et al., 2017). Here this method is used to gain new insights into the surface distribution of water molecules, and to quantitatively assess the destructive effect of clay surfaces on the hydrogen bonding network of water via the calculation of the orientational distributions of $\mathrm{H}_{2} \mathrm{O}$ molecules depending on the distance from the surface.

\section{MODELS AND METHODS}

\subsection{Smectite structures}

In order to explore systematically the effects of smectite composition on the hydrophobicity of their surfaces, several models of dioctahedral smectites were constructed for molecular dynamics (MD) simulations. They differed by total layer charges between 0.1 
and $0.6^{1}$ and by octahedral (montmorillonitic), tetrahedral (beidellitic), and mixed charge localization. Simulations for an uncharged model of pyrophyllite were also performed for comparison. The model structures were built on the basis of the pyrophyllite crystal structure (Lee and Guggenheim, 1981), with isomorphic substitutions introduced at specific atomic sites. The $\mathrm{Mg} / \mathrm{Al}$ ordering in the octahedral sheets was set by maximizing the distance between Mg atoms, following the work of Ortega-Castro et al. (2010). The distribution of $\mathrm{Al} / \mathrm{Si}$ substitutions followed the Lövenstein (1954) rule, i.e. excluding direct $\mathrm{Al}-\mathrm{O}-\mathrm{Al}$ linkages in the tetrahedral sheets.

A smectite model with $12 \times 7 \times 2$ unit cells in the $a, b$, and $c$ crystallographic directions was constructed (for pyrophyllite only one unit cell in the $c$ direction was used). The final simulation cell dimensions were $62.169 \AA \times 62.969 \AA \times 150 \AA$. The $z$ dimension of the cell was intentionally set at a very high value in order to assure that a large free water droplet could be formed on the surface. At the edge of the periodic simulation box in the $z$ direction a graphene layer composed of repulsive carbon atoms was placed to prevent the transfer of $\mathrm{H}_{2} \mathrm{O}$ molecules to the other side of the smectite layer. The number of $\mathrm{H}_{2} \mathrm{O}$ molecules introduced at both sides of the structure was equal to 700 or 350 and initially formed a cuboid just above the 2:1 layers. The Packmol computer program (Martínez et al., 2009) was used to uniformly distribute the $\mathrm{H}_{2} \mathrm{O}$ molecules inside the cuboid. All model structures used in the study are summarized in Table 1.

For each smectite model with a particular structural charge, two cases were considered:

\footnotetext{
${ }^{1}$ The numerical values of the charge throughout this paper are presented in the units of elementary charge $|e|$ per half of the crystallographic unit cell, PHUC.
} 
1) With charge-compensating $\mathrm{Na}^{+}$ions located on both external surfaces and $\mathrm{K}^{+}$ions in the interlayers. The total number of potassium and sodium ions was set to be equal. Additionally, for the montmorillonite model with the highest layer charge of 0.6, the external number of $\mathrm{Na}^{+}$ions was set to correspond to the charge of 0.4 .

2) Without any ions on the external surfaces and only with $\mathrm{K}^{+}$ions located between the clay 2:1 layers as the charge-compensating cations for the entire structure. This artificially imposed distribution of the ions allowed us to separate the effect of the surface cations on the distribution and orientation of the interfacial $\mathrm{H}_{2} \mathrm{O}$ molecules and to quantitatively analyze these molecular distributions as resulting primarily due to the $\mathrm{H}_{2} \mathrm{O}$ interaction with the charged smectite surfaces themselves. In the case of the highly charged models (0.6), some interlayer $\mathrm{K}^{+}$ions had to be replaced by $\mathrm{Ca}^{2+}$ in order to keep the total charge of the simulation cell neutral.

\subsection{Molecular dynamics simulations and their analysis}

Partial atomic charges and other interatomic interaction parameters of smectite layers were described using the ClayFF force field (Cygan et al., 2004) with structural OH groups described by a more accurate Morse potential (Greathouse et al., 2009). Ewald summation (e.g., Allen and Tildesley, 2017) was used to calculate the long range corrections to the electrostatic interactions and the cutoff distance was set to $10.0 \AA$. The $\mathrm{H}_{2} \mathrm{O}$ molecules were described with the SPC model (Beredensen et al., 1981). All simulations were performed using the LAMMPS molecular modeling software package (Plimpton, 1995). Each system was initially brought to a local energy minimum for 10000 steps, followed by a $5 \mathrm{~ns}$ MD run in the $N V T$ statistical ensemble (at constant volume and a temperature of $T=300 \mathrm{~K}$ ). Standard periodic boundary conditions were applied (e.g., Allen and Tildesley, 2017), and the equations of atomic motion were numerically integrated with a time step of $1 \mathrm{fs}$. 
Initial test MD runs for the model structures revealed that for the systems with all ions located in the interlayer between the 2:1 clay layers, some of $\mathrm{SiO}_{4}$ tetrahedra experienced significant deformations: $\mathrm{Si}-\mathrm{O}$ basal distances remained the same, but the $\mathrm{Si}-\mathrm{O}$ apical distance could become too long, apparently due to the quasi-ionic character of the ClayFF parametrization (Cygan et al., 2004). This lead to the mechanical deformation of tetrahedral sheets comparing to real crystallographic structures of the smectite 2:1 layers (see Supplementary materials, Fig. S1). To prevent this from happening, the simulation structures were built based on the pre-optimized (in the $N P T$ ensemble for $0.5 \mathrm{~ns}$, then in the $N V T$ for $0.5 \mathrm{~ns}$ ) pyrophyllite layer and then energy minimized anew. For smectite structures certain atoms were substituted, as necessary, and the layer was replicated and translated into the simulation supercell $12 \times 7 \times 2$, as discussed above. During the production runs all the tetrahedral silicon and aluminum atoms were then fixed at their positions. All other atoms of the smectite structure were not fixed i.e. they were free to move around their crystallographically determined positions according to the modeling force field used. The equilibrium MD-simulated trajectories were recorded every 1 ps during the last 3 ns of each run, and then used to calculate the contact angles of the water droplets formed at the smectite surfaces, according to the following procedure. At first, the center of mass was calculated for the droplets on both sides of the smectite layers for each frame. The density of oxygen atoms of water molecules $\left(\mathrm{O}_{\mathrm{w}}\right)$ was then calculated and centered in $x$ and $y$ directions (parallel to the surface) based on the position of the center of mass, which was taken as the reference point $(0,0)$. The distribution of atoms in the droplet was calculated as a sum from both sides of the smectite layers. Assuming the equivalence of the $x$ - and $y$-directions along the surface, the number of $\mathrm{O}_{\mathrm{w}}$ atoms was then averaged over the $a c$ and $b c$ crystallographic planes in order to obtain a 2dimensional plot. After that, hemispherical plots were calculated as averages over positive and flipped negative positions. A curve enveloping $10-15 \%$ of the maximum density of 
$\mathrm{H}_{2} \mathrm{O}$ molecules in the droplet was drawn and fitted with a circle. Finally, the contact angle was calculated as the tangent to the circle at the point where it crosses the horizontal line corresponding to first layer of surface water molecules along the $z$-direction normal to the surface. Error bars were calculated as a sum of two contributions. The first one is the standard deviation $\left(\sigma_{1}\right)$ of contact angles determined for intervals of $1 \mathrm{~ns}$ in the last $3 \mathrm{~ns}$ of the simulations. These results correspond, therefore, to three fits of enveloping curves and are presented as $2 \sigma_{1}$. The second contribution to the error is $2 \sigma_{2}$ of the contact angles calculated for positions of the first water layer modified by $\pm 0.1 \AA$.

The values of $10-15 \%$ of the maximum density of $\mathrm{H}_{2} \mathrm{O}$ molecules was optimized to give the density of water inside the droplet close to the experimental value at $25^{\circ} \mathrm{C}: 0.997$ $\mathrm{g} / \mathrm{cm}^{3}$. The volume of the droplet was calculated as the volume of the spherical cap (or the volume of sphere minus the volume of the spherical cap, for the contact angles higher than $90^{\circ}$ ). Generally, it should be noted that the exact value of the contact angle depends on the choice of the envelope or distance from the surface at which the tangential line is drawn, but qualitative findings are not affected by this choice within reasonably broad limits.

$$
==\text { Fig. } 1 \text { === }
$$

In order to test if the shape of the droplet (and thus the contact angle) has equilibrated, the measured $10 \%$ enveloping curves were compared for every $1 \mathrm{~ns}$ interval from the beginning of the simulation for pyrophyllite. The initial minimization and the first $0.1 \mathrm{~ns}$ of the NVT run were not taken into account, as these should significantly deviate from equilibrium. A comparison of the five separate envelopes thus obtained (see Supplementary materials Fig. S2) shows that for all intervals the shape is practically identical, with the exception of the very first $1 \mathrm{~ns}$ interval. The second 1-ns interval was also not included in the final contact angle analyses in order to make absolutely sure that the results for the last $3 \mathrm{~ns}$ of 
the simulations correspond to well equilibrated structures.

The MD structural data were also used to calculate the distributions of angles formed by the dipole axes of the $\mathrm{H}_{2} \mathrm{O}$ molecules in the droplet with the vector normal to the 2:1 surfaces (angle $\alpha$ in Fig. 2) as functions of the distance $z$ from the surface. Time-averaged positions of the surface bridging oxygen atoms $\left(\mathrm{O}_{b}\right)$ on the siloxane surface were taken here as the origin $(z=0)$, similarly to the previous studies (Wang et al., 2005b, 2009; Loganathan and Kalinichev, 2013; Szczerba et al., 2014, Ngouana Wakou and Kalinichev, 2014; Greathouse et al., 2015; Teich-McGoldrick et al., 2015). The direction of the $\mathrm{H}_{2} \mathrm{O}$ dipole was defined as the vector from the central point between the two hydrogen atoms of the water molecule to its oxygen atom. As the $\mathrm{HOH}$ angle was allowed to vary in the flexible $\mathrm{H}_{2} \mathrm{O}$ molecular model used, this methodology introduces a minor additional spread of the calculated angles. The ranges of the $\alpha$ angles used in calculations were not set equal but were set to cover the same surface of spherical segment (i.e. narrower ranges for $\alpha$ angles close to $90^{\circ}$, and wider close to $0^{\circ}$ and $180^{\circ}$ ). All these properties were calculated by averaging over the last $3 \mathrm{~ns}$ for each equilibrium MD trajectory.

$$
===\text { Fig. } 2===
$$

\section{RESULTS AND DISCUSSION}

\subsection{Formation of water droplets on the model smectite surfaces}

Dramatically different wetting patterns visually demonstrate the largest difference between the simulation results for the smectite model surfaces where counterions were present and the results for the same smectites where these ions were artificially displaced from the surface into the interlayer (Fig. 3). In the presence of surface ions, a quite homogeneous flat water film is forming indicating complete wetting of the smectite surface (Fig. 3a). The more surface $\mathrm{Na}^{+}$ions are present, the less rugged is the boundary interface 
between the water film and the "vapour phase" above it (see Supplementary materials, Figs S3-S6). In the case of smectites with relatively low charge $(\leq 0.2)$, there are some areas on the surface that are temporarily exposed and not covered with water. However, this effect is not observed for higher layer charge models with the same number of surface water molecules. On the other hand, with no ions present on the surface, its wetting becomes much less evident, and a distinct water droplet is always formed (Fig. 3 right panel).

$$
===\text { Fig. } 3 \text { === }
$$

In all the studied cases the increased density of water molecules next to the surface is clearly visible (Figs. 1, 4, 5, 6). This corresponds to the first layer of $\mathrm{H}_{2} \mathrm{O}$ molecules on the surface. A second layer of surface water molecules is also visible, while a third one is barely distinguishable. Between the first two interfacial water layers, a layer of low density is observed, which is also manifested in the curve on the envelope corresponding to $10 \%$ of the maximum density of $\mathrm{O}_{\mathrm{w}}$ molecules (Figs. 1, 4, 5, 6). These features, of course, correspond to the maxima and minima of the atomic density profiles as functions of distance from the surface (e.g., Wang et al., 2005b, 2009; Loganathan and Kalinichev, 2013).

\subsection{Contact angles of the water droplets on montmorillonite and beidellite surfaces devoid} of ions

On the montmorillonite surfaces devoid of ions, a water droplet of a hemi-spherical shape is always formed. Calculations based on the time-averaged shapes of the droplets show that the contact angles for montmorillonites are very similar or lower than the ones obtained for pyrophyllite $-106^{\circ}$ (Figs. 1 and 4). For montmorillonite with the charge of 0.5 , two simulations were performed, differing in the ways $\mathrm{Mg}$ atoms in the octahedral sheet were ordered. Significantly higher contact angle was observed for the structure characterized by 
highly ordered substitutions in the octahedral sheet $-106.6^{\circ}$ (Fig. 4), while the structure with the same layer charge but with disordered substitutions shows a much lower contact angle of $97.2^{\circ}$. This is probably an effect of decreased adhesion between water molecules and the surface, which is related to the ordering of charges in the 2:1 layers. Because of this effect of ordering, there can be no clear dependence of the contact angle on the layer charge for different montmorillonites (Fig. 4). Summarizing, it is clear from the calculations, that the contact angles of water droplets on the surfaces of montmorillonite over a pretty broad range of structural charges (but devoid of ions located directly on the surface) are only slightly lower than those for electrostatically neutral pyrophyllite - on average by about $5-10^{\circ}$.

$$
===\text { Fig. } 4 \text { === }
$$

The tetrahedral charge introduced in the 2:1 layers by $\mathrm{Al} / \mathrm{Si}$ substitutions leads to a noticeable decrease of the surface hydrophobicity. For beidellites the calculated contact angles are significantly lower than for pyrophyllite (Fig. 5). These are also highly dependent on the layer charge: i.e. the higher the charge the lower the angle. The only exception from this trend is beidellite with the highest charge of 0.6 , which shows a slightly higher contact angle than for a beidellite structure with the of 0.5 . This can also be due to an ordering effect similar to the one observed for montmorillonites. Because of these lower contact angles all the calculations for beidellites were performed with lower water content $\left(350 \mathrm{H}_{2} \mathrm{O}\right.$ vs. 700 for montmorillonites, on each side of the layer). For higher water content, the shape of the coverage is different: instead of a spherical droplet formation, the surface water coverage spreads all the way to the edges of the simulation cell, and the calculation of the contact angle becomes biased because of the limited size of the surface and the periodic boundary conditions imposed on the system. 


\subsection{Effect of the tetrahedral-to-octahedral substitutions ratio on the contact angles}

In order to more clearly quantify the effect of tetrahedral vs. octahedral substitutions on the contact angle, simulations with total layer charge of 0.6 but with different proportion between tetrahedral and octahedral substitutions were additionally performed (Fig. 6). Because of the lower water content $\left(350 \mathrm{H}_{2} \mathrm{O}\right.$ molecules), the contact angle can be somewhat different than for the structure with $700 \mathrm{H}_{2} \mathrm{O}$ molecules on each side of the smectite layers (Mtm06_no_surf_ions in Figs. 4 and 6). The difference, although important, does not affect significantly the qualitative picture emerging from the simulations.

The results (Fig. 6) show a significant decrease of the contact angles with increasing beidellitic (tetrahedral) layer charge component. A small effect of the octahedral substitution can also be observed: the angles are $\sim 5-10^{\circ}$ lower if there is additional contribution of the charge from the octahedral sheet (Figs. 5 and 6).

$$
===\text { Fig. } 6===
$$

All these results indicate that the charge of the 2:1 layer originating from the octahedral sheet does not significantly affect the hydrophobic properties of the surface, compared to that of pyrophillite. Mechanistically, within the ClayFF model (Cygan et al., 2004), this can be explained by the fact that the charges of the surface atoms in contact with the interfacial $\mathrm{H}_{2} \mathrm{O}$ molecules water phase are the same. Tetrahedral substitutions introduce some excess negative charge directly at the surface. Within the ClayFF model, this is due to the less positive charge of the surface metal (1.575 for $\mathrm{Al}$ vs 2.1 for $\mathrm{Si}$ ) and more negative charges of the oxygen atoms surrounding this substituted site $(-1.6875$ vs -1.05$)$. Thus, the smectite surface becomes more polar, and this modifies its hydrophobic properties. In order to 
more deeply explain origin of this phenomenon, calculations of plots showing orientation of water molecules on the surfaces were performed.

\section{4. $\mathrm{H}_{2} \mathrm{O}$ molecular orientations at the smectite surfaces in the presence of counterions}

For simulations of smectite models with surface ions, the contour maps of the angular distributions of the interlayer $\mathrm{H}_{2} \mathrm{O}$ dipole vectors with respect to the direction normal to the surface and as a function of the distance $z$ from the surface allow to distinguish two surfaceoriented types of $\mathrm{H}_{2} \mathrm{O}$ molecules: monodentate and bidentate. In the bidentate orientation, a water molecule donates two weak hydrogen bonds to the surface oxygens, while in the monodentate orientation it can donate only one H-bond to the surface. In the two-dimensional plots of the angular distributions (Fig. 7), the bidentate population is located somewhat closer to the surface at $z \sim 2.0 \AA$ and is characterized by the angles $\alpha \sim 0-20^{\circ}$. At the same time, the monodentate population is observed at distances $z \sim 2.6 \AA$ and is characterized by a broader distribution of angles between $30^{\circ}$ and $80^{\circ}$ with a maximum at $\alpha \sim 50^{\circ}$. The presence of monodentate $\mathrm{H}_{2} \mathrm{O}$ molecules is ubiquitous, while the bidentate $\mathrm{H}_{2} \mathrm{O}$ population is observed mainly for smectites with higher layer charge. This is consistent with earlier results for muscovite (Wang et al., 2005b, 2009; Loganathan and Kalinichev, 2013) and for smectites (Szczerba et al., 2016).

As the number of water molecules on the surface was the same for all the simulated structures, it is also visible in Fig. 7 that the thickness of the water film shows dependence on the number of ions: the more the ions are on the surface, the thinner and more densely packed is the interfacial water film. For example: in the case of Mtm02 the envelope corresponding to $90 \%$ of the total number of $\mathrm{O}_{\mathrm{w}}$ atoms (second envelope line) extends to distances about $9.2 \AA$ from the surface, while for Mtm05 this value is only about $6.2 \AA$ (Fig. 7). In the case of beidellites the trends are practically the same. The main difference is in the distribution of the 
surface ions, which tends to be much closer to the surface, than in the case of montmorillonite structures.

$===$ Fig. 7 ===

All previous simulations assumed that the layer charge is fully balanced by the interlayer and surface cations. In the structure Mtm06_surface_04 the layer charge was 0.6, while the number of surface ions was lower and corresponded to 0.4. For this structure the distribution of angles and cation density are corresponding to those of Mtm04 model and the number of $\mathrm{H}_{2} \mathrm{O}$ molecules in bidentate population is clearly lower than for Mtm05 (Fig. 7). This result demonstrates how significantly and directly the orientation of interfacial $\mathrm{H}_{2} \mathrm{O}$ molecules and the distribution of cations on montmorillonite surfaces depend on the total number of ions present, and not on the absolute layer charge. The thickness of the interfacial water film is also directly dependent on the number of ions and not on the layer charge: the maximum of the envelope corresponding to $90 \%$ of the total number of $\mathrm{O}_{\mathrm{w}}$ atoms extends to distances about 6.5 A for both Mtm06_surface_04 and Mtm04 smectite models.

\section{5. $\mathrm{H}_{2} \mathrm{O}$ molecular orientations at the smectite surfaces devoid of counterions}

The angular distributions of the interlayer $\mathrm{H}_{2} \mathrm{O}$ dipole vectors with respect to the direction normal to the smectite surfaces devoid of ions (Fig. 8) are dramatically different from those in the presence of ions (Fig. 7). For all montmorillonite models, the distributions look practically identical: no difference between smectites with higher or lower charges are observed. The distributions are centered around $z \sim 3.0 \AA$ and $\alpha \sim 90^{\circ}$. This larger distance from the surface indicates that the lack of ions leads to an increased hydrophobicity of the surface, or, in other words, to a decreased $\mathrm{H}_{2} \mathrm{O}$ affinity towards the surface. There is also no 
distinct contribution from neither bidentate nor monodentate $\mathrm{H}_{2} \mathrm{O}$ orientations, contrary to what was observed for montmorillonites with counterions on the surface.

In the case of beidellite surfaces an additional non-negligible contribution from $\mathrm{H}_{2} \mathrm{O}$ molecules at $z \sim 2.6 \AA$ and $\alpha \sim 50^{\circ}$ is also visible (Fig. 8). Relative intensity of this maximum is increasing with increasing number of tetrahedral substitutions, while its position is not dependent on the layer charge. This additional sub-population is clearly responsible for increasing $\mathrm{H}_{2} \mathrm{O}$ affinity towards the beidellitic surface, thus also for decreasing contact angle of the water droplet (Fig. 5).

$===$ Fig. 8 ===

In order to get further insight into the origin of this additional sub-population, distributions of $\mathrm{H}_{2} \mathrm{O}$ molecular orientations for the structure with and without ions were compared. For example, in the case of Beid05, monodentete and bidentate populations are clearly visible (Fig. 9, left panel). However, for the Beid05_no_surf_ions model, there is no bidentate population, but there is a "hydrophobic" population instead, with both hydrogens of $\mathrm{H}_{2} \mathrm{O}$ oriented away from the surface. Distances from the surface and angles $\alpha$ are practically identical between this additional sub-population for Beid05_no_surf_ions model and the monodentate population of the Beid05 model. This indicates that it is specifically the population of monodentate water molecules which is responsible for decrease of hydrophobicity of beidellitic smectites.

$===$ Fig. $9===$

Relation of the positions of $\mathrm{H}_{2} \mathrm{O}$ molecules contributing to this monodentate subpopulation to the positions of $\mathrm{Al} / \mathrm{Si}$ substitutions in tetrahedral sheet indicates that it is 
concentrated only around charge deficient $\mathrm{Al}^{3+}$ sites (Fig. 10). In contrast, the water molecules contributing to the population of "hydrophobic" orientations tend to be located mainly above the centers of $\mathrm{SiO}_{4}$ tetrahedra and also above the hexagonal cavities on the siloxane surface. There is practically no "hydrophobic" water molecules above $\mathrm{AlO}_{4}$ tetrahedra.

$$
===\text { Fig. } 10===
$$

\subsection{Factors affecting hydrophobicity of smectite surfaces}

The simulation results show that the hydrophobicity (or hydrophilicity) of smectite surfaces is controlled primarily by the presence of ions that balance the negative charge of the 2:1 layer. The hydrophobicity of bare smectite surfaces themselves, without the counterions present, closely resembles that of hydrophobic pyrophyllite. However, if the structural charge originates from the tetrahedral sheet (i.e., closer to the aqueous interface), the surfaces are more hydrophilic and the contact angle is below $90^{\circ}$. Nevertheless, it is still significantly above $0^{\circ}$, indicating that the situation is still far from complete wetting which is observed for smectite surfaces in the presence of charge balancing cations.

This effect is clearly related to the fact that the ions, due to electrostatic interactions, tend to be located as close as possible to the charged surface. There is, however, an opposite force limiting the ions ability to approach smectite surfaces too closely, which is the hydration enthalpy, that can be highly negative (e.g., $-99.9 \mathrm{kcal} / \mathrm{mol}$ for for $\mathrm{Na}^{+}$). Therefore, the ions attract $\mathrm{H}_{2} \mathrm{O}$ molecules, and quite strongly hold them in their hydration spheres, which prevents their direct contact with the charged surface. The orientation of water molecules around ions is then rearranged and $\mathrm{H}_{2} \mathrm{O}$ can form hydrogen bonds with the surface. These $\mathrm{H}-$ bonds are, however, relatively weak compared to H-bonds in bulk liquid water (e.g., Szczerba et. al,, 2016). 
It is the number of surface cations that most significantly affects the orientation of interfacial water molecules, which is clearly manifested in the comparison of the simulation results between the Mtm04 and Mtm06_surface_04 smectite models. Even with the montmorillonitic charge being higher by $50 \%$ in the latter case, if the number of surface cations is the same, the orientational distribution of interfacial $\mathrm{H}_{2} \mathrm{O}$ molecules and the distribution of ions as function of distance from the surface remains practically identical (Fig. 7). In nature however, the number of surface ions is of course directly related to the smectite layer charge, so these two effects cannot be observed separately, except is such model simulations.

\subsection{Charge polarization in natural samples.}

Of course, smectites with negatively charged layers, but without adsorbed cations are impossible to find in nature. However, in the case of illitic particles, that are formed by the process of smectite illitization, the model can possibly be, to some extent, similar to the one presented in this manuscript.

In the case of illite-smectite (I/S) particles, Środon et al. (2009) found that smectitic charge is independent on the percent of smectite in I/S and is close to 0.41 , while illitic interlayer has also stable charge of 0.95 . More recently, a constant value of smectitic surface charge of $\mathrm{I} / \mathrm{S}(0.47 \pm 0.03)$ was confirmed independently, using IR spectroscopy, by Kuligiewicz et al., (2018). Theoretically, if there can be more effective binding of potassium ions in the "illitic" interlayers, the measured "smectitic" charge should thus be effectively smaller. This is clearly shown in Fig. 7 for Mtm06 with the layer charge of 0.6, but with the surface charge of 0.4 . The distributions of cations and water molecules are practically identical to the case of Mtm04, with the layer charge of 0.4 . This effect can possibly be responsible, to some extent, for constant values of the "smectitic" surface charges of I/S, 
being unaffected by percentage of smectite layers in $\mathrm{I} / \mathrm{S}$, and also for the variation of "smectitic" charge with illite crystal size fraction (Kuligiewicz et al., 2018).

\section{CONCLUSIONS}

(1) Molecular dynamics simulations show that if montmorillonite surface could be devoid of ions, it would be practically as hydrophobic as that of pyrophyllite. For negatively charged montmorillonite surfaces, if no charge balancing cations are present, a water droplet would be formed with contact angles just slightly lower $\left(\sim 15^{\circ}\right.$ at most $)$ than that for completely neutral pyrophyllite.

(2) Bare beidellitic surfaces have lower hydrophobicity than similarly charged montmorillonitic surfaces, and their contact angles can be as low as $60^{\circ}$.

(3) The highly hydrophilic character of smectite surfaces observed in experiments is, therefore, almost entirely due to the presence of charge balancing cations on the surface.

(4) The orientation of $\mathrm{H}_{2} \mathrm{O}$ molecules nearest to the surface vary significantly between a typical smectite surface and the same surface from which all counterions are removed (moved to the interlayer while keeping the same amount of charge). In the presence of counterions, there are two distinct $\mathrm{H}_{2} \mathrm{O}$ populations nearest to the surface: with one and two molecular $\mathrm{O}-\mathrm{H}$ bonds oriented towards the surface, thus forming with it one (monodentate) or two (bidentate) H-bonds. However, on the surface without ions, the dominant angles formed by the $\mathrm{H}_{2} \mathrm{O}$ dipole and the vector normal to the $2: 1$ surface are close to $90^{\circ}$. On beidellite surfaces additional monodentate $\mathrm{H}_{2} \mathrm{O}$ population is also observed.

(5) The simulation results clearly demonstrate that the notion of hydrophobicity or hydrophilicity of the smectite surface depends, essentially, on the decision how the surface is defined. If we consider the smectite surfaces by themselves, devoid if the counterions, the bare 2:1 surface is hydrophobic or only moderately hydrophilic. However, if the counterions 
are considered as integral part of the surface, then the smectite surfaces are highly

484 hydrophilic, which is, of course, what is observed in nature. These findings could be helpful

\section{ACKNOWLEDGMENTS}

The authors would like to thank to PLGRID and PRACE infrastructure for providing computer time for calculations. A.G.K. also acknowledges support of the industrial chair "Storage and Disposal of Radioactive Waste" at the Institut Mines-Télécom Atlantique, funded by ANDRA, Orano, and EDF, and the HSE University Basic Research Program funded by the Russian Academic Excellence Project "5-100". 


\section{REFERENCES}

Allen, M.P., Tildesley, D.J., 2017. Computer Simulation of Liquids. $2^{\text {nd }}$ edition, Oxford University Press, New York, 626 pp.

Arab, M., Bougeard, D., Smirnov, K.S., 2003. Structure and dynamics of the interlayer water in an uncharged 2:1 clay. Phys. Chem. - Chem. Phys. 5, 4699-4707.

Berendsen, H.J.C., Postma, J.P.M., van Gunsteren, W.F., Hermans, J., 1981. Interaction models for water in relation to protein hydration. In: Intermolecular Forces (B. Pullman, editor). D. Reidel, Dordrecht, The Netherlands, 331-342.

Bridgeman, C.H., Skipper, N.T., 1997. A Monte Carlo study of water at an uncharged clay surface. J. Physics - Cond. Matter 9, 4081-4087.

Churakov, S.V., 2006. Ab initio study of sorption on pyrophyllite: Structure and acidity of the edge sites. J. Phys. Chem. B 110, 4135-4146.

Cygan, R.T., Liang, J.J., Kalinichev, A.G., 2004. Molecular models of hydroxide, oxyhydroxide, and clay phases and the development of a general force field. J. Phys. Chem. B 108, 1255-1266.

Dazas, B., Lanson, B., Breu, J., Robert, J.-L., Pelletier, M., Ferrage, E., 2013. Smectite fluorination and its impact on interlayer water content and structure: A way to fine tune the hydrophilicity of clay surfaces? Micropor. Mesopor. Mater. 181, 233-247.

Dazas, B., Lanson, B., Delville, A., Robert, J.-L., Komarneni, S., Michot, L.J., Ferrage, E., 2015. Influence of tetrahedral layer charge on the organization of interlayer water and ions in synthetic Na-saturated smectites. J. Phys. Chem. C 119, 4158-4172.

Giovambattista, N., Debenedetti, P.G. and Rossky, P.J., 2007. Effect of surface polarity on water contact angle and interfacial hydration structure. J. Phys. Chem. B 111, 95819587. 
Greathouse, J.A., Durkin, J.S., Larentzos, J.P., Cygan, R.T., 2009. Implementation of a Morse potential to model hydroxyl behavior in phyllosilicates. J. Chem. Phys. 130, 134713.

Greathouse, J.A., Hart, D.B., Bowers, G.M., Kirkpatrick, R.J., Cygan, R.T., 2015. Molecular simulation of structure and diffusion at smectite-water interfaces: Using expanded clay interlayers as model nanopores. J. Phys. Chem. C, 119, 17126-17136.

Greathouse, J. A., Boyle, T. J., Kemp, R. A., 2018. Computational evaluation of Mg-salen compounds as subsurface fluid tracers: Molecular dynamics simulations in toluenewater mixtures and clay mineral nanopores. Energy \& Fuels 32, 4969-4978.

Hartkamp, R., Biance, A.-L., Fu, L., Dufreche, J.-F., Bonhomme, O., Joly, L., 2018. Measuring surface charge: Why experimental characterization and molecular modeling should be coupled. Current Opinion Coll. \& Interf. Sci. 37, 101-114.

Harvey, J.A., Johnston, C.T., Criscenti, L.J., Greathouse, J.A., 2019. Distinguishing between bulk and edge hydroxyl vibrational properties of 2:1 phyllosilicates via deuteration. Chem. Commun. 55, 3453-3456.

Jaynes, W.F., Boyd, S.A., 1991. Hydrophobicity of siloxane surfaces in smectites as revealed by aromatic hydrocarbon adsorption from water. Clays Clay Min. 39, 428-436.

Khalkhali, M., Kazemi, N., Zhang, H., Liu, Q., 2017. Wetting at the nanoscale: A molecular dynamics study. J. Chem. Phys. 146, 114704.

Kuligiewicz, A., Derkowski, A., Szczerba, M., Gionis, V., Chryssikos, G.D., 2015. Revisiting the infrared spectrum of the water-smectite interface. Clays Clay Min. 63, 15-29.

Kuligiewicz, A., Derkowski, A., Srodon, J., Gionis, V., Chryssikos, G.D., 2018. The charge of wettable illite-smectite surfaces measured with the O-D method. Appl. Clay Sci. 161, 354-363.

Lee, J.H., Guggenheim, S., 1981. Single crystal X-ray refinement of pyrophyllite-1Tc. Amer. Mineral. 66, 350-357. 
Liu, X., Lu, X., Yang, K., Hubble, T.C.T., Hou, Q., 2007. Monte Carlo simulations of surface energy of the open tetrahedral surface of 2:1-type phyllosilicate. J. Coll. Interf. Sci. $307,17-23$.

Liu, Z., Ghatkesar, M. K., Sudholter, E. J. R., Singh, B., Kumar, N., 2019. Understanding the cation-dependent surfactant adsorption on clay minerals in oil recovery. Energy \& Fuels 33, 12319-12329.

Loganathan, N., Kalinichev, A.G., 2013. On the hydrogen bonding structure at the aqueous interface of ammonium-substituted mica: A molecular dynamics simulation. Zeitschrift für Naturforschung 68A, 91-100.

Lövenstein, W., 1954. The distribution of aluminum in the tetrahedra of silicates and aluminates. Amer. Mineral. 39, 92-96.

Martínez, L., Andrade, R., Birgin, E.G., Martínez, J.M., 2009. Packmol: A package for building initial configurations for molecular dynamics simulations. J. Comp. Chem. $30,2157-2164$.

Michot, L.J., Villieras, F., Francois, M., Yvon, J., Le Dred, R., Cases, J.M., 1994. The structural microscopic hydrophilicity of talc. Langmuir 10, 3765-3773.

Myshakin, E. M., Cygan, R. T., 2018. Monte Carlo and molecular dynamics simulations of clay mineral systems. In: Greenhouse Gases and Clay Minerals. Romanov, V., Ed. Springer, 2018, 147-174.

Ngouana Wakou, B.F., Kalinichev, A.G., 2014. Structural arrangements of isomorphic substitutions in smectites: Molecular simulation of the swelling properties, interlayer structure, and dynamics of hydrated Cs-montmorillonite revisited with new clay models. J. Phys. Chem. C 118, 12758-12773. 
Ortega-Castro, J., Hernández-Haro, N., Dove, M.T., Hernández-Laguna, A., Saínz-Diaz, C.I., 2010. Density functional theory and Monte Carlo study of octahedral cation ordering of $\mathrm{Al} / \mathrm{Fe} / \mathrm{Mg}$ cations in dioctahedral 2:1 phyllosilicates. Amer. Mineral. 95, 209-220.

Ou, X., Lin, Z., Li, J., 2018. Surface microstructure engenders unusual hydrophobicity in phyllosilicates. Chem. Commun. 54, 5418-5421.

Plimpton, S., 1995. Fast parallel algorithms for short-range molecular dynamics. J. Comp. Phys. 117, 1-19.

Rotenberg, B., Patel, A.J. Chandler, D., 2011. Molecular explanation for why talc surfaces can be both hydrophilic and hydrophobic. J. Amer. Chem. Soc. 133, 20521-20527.

Shen, W., Li, L., Zhou, H., Zhou, Q., Chen, M., Zhu, J., 2017. Effects of charge density on the hydration of siloxane surface of montmorillonite: A molecular dynamics simulation study. Appl. Clay Sci. 159, 10-15.

Silkina, E.F., Asmolov, E.S. Vinogradova, O.I., 2019. Electro-osmotic flow in hydrophobic nanochannels. Phys. Chem. - Chem. Phys. 21, 23036-23043.

Smirnov, K.S., 2017a. A molecular dynamics study of the interaction of water with the external surface of silicalite-1. Phys. Chem. - Chem. Phys. 19, 2950-2960.

Smirnov, K.S., 2017b. A modeling study of methane hydrate decomposition in contact with the external surface of zeolites. Phys. Chem. - Chem. Phys. 19, 23095-23105.

Sobolev, O., Favre Buivin, F., Kemner, E., Russina, M., Beuneu, B., Cuello, G.J., Charlet, L., 2010. Water-clay surface interaction: A neutron scattering study. Chem. Phys. 374, 5561.

Šolc, R., Gerzabek, M.H., Lischka, H., Tunega, D., 2011. Wettability of kaolinite (001) surfaces - Molecular dynamic study. Geoderma 169, 47-54.

Sposito, G., Skipper, N.T., Sutton, R., Park, S-H., Soper, A.K., Greathouse, J.A., 1999. Surface geochemistry of clay minerals. Proc. Nat. Acad. Sci. USA 96, 3358-3364. 
Szczerba, M., Kłapyta, Z., Kalinichev, A.G., 2014. Ethylene glycol intercalation in smectites. Molecular dynamics simulation studies. Appl. Clay Sci. 91, 87-97.

Szczerba, M., Kuligiewicz, A., Derkowski, A., Gionis, V., Chryssikos, G.D., Kalinichev, A.G., 2016. Structure and dynamics of water-smectite interfaces: hydrogen bonding and the origin of the sharp O-Dw/O-Hw infrared band from molecular simulations. Clays Clay Min. 64, 452-471.Środoń, J., Zeelmaekers, E., Derkowski, A., 2009. The charge of component layers of illite-smectite in bentonites and the nature of end-member illite, Clays Clay Min. 57, 649-671.

Teich-McGoldrick, S.L., Greathouse, J.A., Jové-Colón, C.F., Cygan, R.T., 2015. Swelling properties of montmorillonite and beidellite clay minerals from molecular simulation: Comparison of temperature, interlayer cation, and charge location effects. J. Phys. Chem. C 119, 20880-20891.

Tenney, C. M., Cygan, R. T., 2014. Molecular simulation of carbon dioxide, brine, and clay mineral interactions and determination of contact angles. Env. Sci. Techn. 48, 20352042.

Tunega, D., Benco, L., Haberhauer, G., Gerzabek, M.H., Lischka, H., 2002. Ab initio molecular dynamics study of adsorption sites on the (001) surfaces of 1:1 dioctahedral clay minerals. J. Phys. Chem. B 106, 11515-11525.

Tunega, D., Gerzabek, M.H., Lischka, H., 2004. Ab initio molecular dynamics study of a monomolecular water layer on octahedral and tetrahedral kaolinite surfaces. J. Phys. Chem. B 108, 5930-5936.

Wang, J.W., Kalinichev, A.G., Kirkpatrick, R.J., 2004. Molecular modeling of the 10angstrom phase at subduction zone conditions. Earth Planet. Sci. Lett. 222, 517-527.

Wang, J.W., Kalinichev, A.G., Kirkpatrick, R.J., 2005a. Structure and decompression melting of a novel, high-pressure nanoconfined 2-D ice. J. Phys. Chem. B 109, 14308-14313. 
Wang, J., Kalinichev, A.G., Kirkpatrick, R.J., Cygan, R.T., 2005b. Structure, energetics, and dynamics of water adsorbed on the muscovite (001) surface: a molecular dynamics simulation. J. Phys. Chem. B 109, 15893-15905.

Wang, J., Kalinichev, A.G., Kirkpatrick, R.J., 2009. Asymmetric hydrogen bonding and orientational ordering of water at hydrophobic and hydrophilic surfaces: A comparison of water/vapor, water/talc, and water/mica interfaces. J. Phys. Chem. C 113, 1107711085.

Willemsen, J.A.R., Myneni, S.C.B., Bourg, I.C., 2019. Molecular dynamics simulations of the adsorption of phthalate esters on smectite clay surfaces. J. Phys. Chem. C, 123, 1362413636.

Xi, E., Venkateshwaran, V., Li, L., Rego, N., Patel, A.J., Garde, S., 2017. Hydrophobicity of proteins and nanostructured solutes is governed by topographical and chemical context. Proc. Nat. Acad. Sci. USA 114, 13345-13350.

Yi, H., Zhao, Y., Liu, Y., Wang, W., Song, S., Liu, C., Li, H., Zhan, W., Liu, X., 2019. A novel method for surface wettability modification of talc through thermal treatment. Appl. Clay Sci. 176, 21-28.

Zhang, L., Lu, X., Liu, X., Yang, K., Zhou, H., 2016. Surface wettability of basal surfaces of clay minerals: Insights from molecular dynamics simulation. Energy \& Fuels 30, 149160.

Zheng, Y., Zaoui, A., 2017. Wetting and nanodroplet contact angle of the clay 2:1 surface: The case of Na-montmorillonite (001). Appl. Surf. Sci. 396, 717-722.

Zhou, C.H., Cun Jun, L., Gates, W.P., Zhu, T.T., Wei Hua, Y., 2019. Co-intercalation of organic cations/amide molecules into montmorillonite with tunable hydrophobicity and swellability. Appl. Clay Sci. 179, 105157. 
Fig. 1. Methodology of the contact angle calculation.

Fig. 2. Definition of the $\alpha$ angle.

Fig. 3. Comparison of final snapshots obtained for montmorillonite with the same structural charge of 0.3 , but with the $\mathrm{Na}^{+}$ions present on the surface (left) or replaced with $\mathrm{K}^{+}$and hidden in the interlayer between the 2:1 layers of smectite (right).

Fig. 4. Distribution of oxygen atoms in the water droplets $\left(\mathrm{O}_{\mathrm{w}}\right)$ formed by $700 \mathrm{H}_{2} \mathrm{O}$ molecules on the basal surfaces of montmorillonite devoid of the counterions. The envelope corresponds to $90 \%$ of the total number of $\mathrm{O}_{\mathrm{w}}$ atoms. The contact angle for each structure is marked with corresponding tangent straight line. The distributions of $\mathrm{Mg} / \mathrm{Al}$ substitutions in the octahedral sheet of montmorillonites is shown in the insets.

Fig. 5. Distribution of oxygen atoms in the water droplets $\left(\mathrm{O}_{\mathrm{w}}\right)$ formed by $350 \mathrm{H}_{2} \mathrm{O}$ molecules and the contact angles on beidellite surfaces devoid of the ions.

Fig. 6. Distribution of oxygen atoms in water droplets $\left(\mathrm{O}_{\mathrm{w}}\right)$ formed by $350 \mathrm{H}_{2} \mathrm{O}$ molecules and contact angles on mixed montmorillonite-beidellite surfaces devoid of the ions.

Fig. 7. Distributions of the $\mathrm{H}_{2} \mathrm{O}$ dipole vector orientations ( $\alpha$, left axes) as function of the distance from the surface $(z)$ for various smectite surfaces in the presence of counterions. The blue curves and the left axes show the cation density profiles. $700 \mathrm{H}_{2} \mathrm{O}$ molecules on each side of the smectite structure was assumed.

Fig. 8. Distributions of the $\mathrm{H}_{2} \mathrm{O}$ dipole vector orientations $(\alpha)$ as function of the distance from the surface $(z)$ for various smectite surfaces devoid of counterions. $700 \mathrm{H}_{2} \mathrm{O}$ molecules on each side of the smectite structure was assumed.

Fig. 9. Distributions of the $\mathrm{H}_{2} \mathrm{O}$ dipole vector orientations $(\alpha)$ as function of the distance from the surface $(z)$ for Beid05 structures with and without the counterions on the surface. The positions of all maxima are marked. Close correspondence of the monodentate sub-populations for both structures are clearly visible.

Fig. 10. Distribution of oxygens of $\mathrm{H}_{2} \mathrm{O}$ molecules for two sub-populations on the surface of Beid02_no_surf_ions. The specific ranges of distance $\mathrm{z}$ and angle $\alpha$ are indicated in parentheses. Black triangles correspond to the positions of $\mathrm{Al} / \mathrm{Si}$ substitutions and light grey triangles $-\mathrm{Si}^{4+}$ positions of the tetrahedral sheet. 


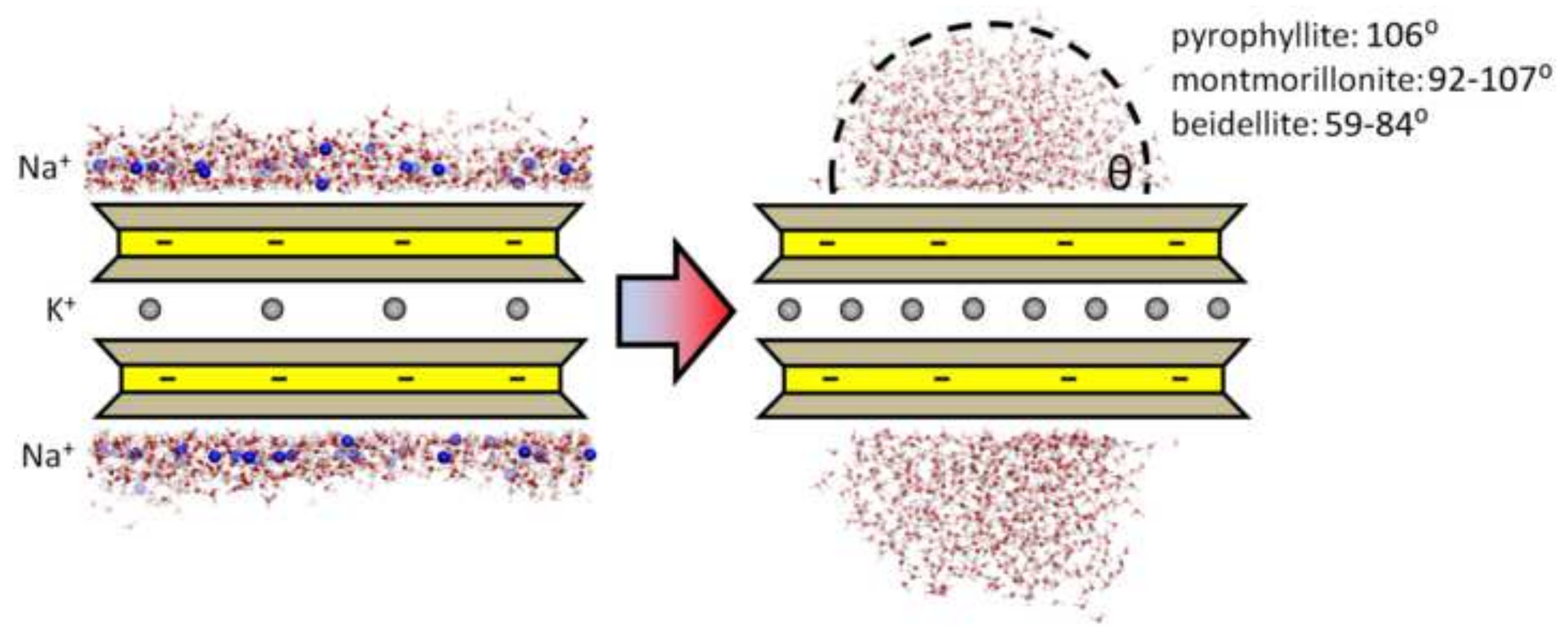


(1) Montmorillonite surface devoid of ions is hydrophobic.

(2) Beidellite surface devoid of ions is moderately hydrophilic.

(3) Highly hydrophilic smectite surfaces are due to the presence of cations.

(4) In the presence of cations, there are two distinct $\mathrm{H}_{2} \mathrm{O}$ populations on the surface.

(5) On the surface devoid of ions, there is dominant "hydrophobic" $\mathrm{H}_{2} \mathrm{O}$ population. 
Table 1. Smectite model structures used in the study.

\begin{tabular}{|c|c|c|c|c|}
\hline Model & $\begin{array}{l}\text { Layer charge } \\
\text { (PHUC) }\end{array}$ & $\begin{array}{l}\text { No of } \\
\text { external } \\
\text { surface ions }\end{array}$ & $\begin{array}{l}\text { No of interlayer } \\
\text { ions }\end{array}$ & $\begin{array}{l}\text { Number of } \\
\text { water } \\
\text { molecules } \\
\text { in droplet }\end{array}$ \\
\hline Pyrophyllite & 0.0 & 0 & 0 & 700 \\
\hline $\mathrm{Mtm02}$ & 0.2 & $34\left(\mathrm{Na}^{+}\right)$ & $34\left(\mathrm{~K}^{+}\right)$ & 700 \\
\hline Mtm03 & 0.3 & $50\left(\mathrm{Na}^{+}\right)$ & $50\left(\mathrm{~K}^{+}\right)$ & 700 \\
\hline Mtm04 & 0.4 & $68\left(\mathrm{Na}^{+}\right)$ & $68\left(\mathrm{~K}^{+}\right)$ & 700 \\
\hline Mtm05 & 0.5 & $84\left(\mathrm{Na}^{+}\right)$ & $84\left(\mathrm{~K}^{+}\right)$ & 700 \\
\hline Mtm05_order & 0.5 (ordered) & $84\left(\mathrm{Na}^{+}\right)$ & $84\left(\mathrm{~K}^{+}\right)$ & 700 \\
\hline Mtm06_surface_04 & 0.6 & $66\left(\mathrm{Na}^{+}\right)$ & $134\left(\mathrm{~K}^{+}\right)$ & 700 \\
\hline Mtm02_no_surf_ions & 0.2 & 0 & $68\left(\mathrm{~K}^{+}\right)$ & 700 \\
\hline Mtm03_no_surf_ions & 0.3 & 0 & $100\left(\mathrm{~K}^{+}\right)$ & 700 \\
\hline Mtm04_no_surf_ions & 0.4 & 0 & $134\left(\mathrm{~K}^{+}\right)$ & 700 \\
\hline Mtm05_no_surf_ions & 0.5 & 0 & $168\left(\mathrm{~K}^{+}\right)$ & 700 \\
\hline Mtm05_order_no_surf_ions & 0.5 (ordered) & 0 & $168\left(\mathrm{~K}^{+}\right)$ & 700 \\
\hline Mtm06_no_surf_ions & 0.6 & 0 & $136\left(\mathrm{~K}^{+}\right) 32\left(\mathrm{Ca}^{2+}\right)$ & 700 \\
\hline Beid01 & 0.1 & $18\left(\mathrm{Na}^{+}\right)$ & $18\left(\mathrm{~K}^{+}\right)$ & $350(700)^{a}$ \\
\hline Beid02 & 0.2 & $34\left(\mathrm{Na}^{+}\right)$ & $34\left(\mathrm{~K}^{+}\right)$ & $350(700)^{a}$ \\
\hline Beid03 & 0.3 & $50\left(\mathrm{Na}^{+}\right)$ & $50\left(\mathrm{~K}^{+}\right)$ & $350(700)^{a}$ \\
\hline Beid04 & 0.4 & $68\left(\mathrm{Na}^{+}\right)$ & $68\left(\mathrm{~K}^{+}\right)$ & $350(700)^{a}$ \\
\hline Beid05 & 0.5 & $84\left(\mathrm{Na}^{+}\right)$ & $84\left(\mathrm{~K}^{+}\right)$ & $350(700)^{a}$ \\
\hline Beid01_no_surf_ions & 0.1 & 0 & $36\left(\mathrm{~K}^{+}\right)$ & 350 \\
\hline Beid02_no_surf_ions & 0.2 & 0 & $68\left(\mathrm{~K}^{+}\right)$ & 350 \\
\hline Beid03_no_surf_ions & 0.3 & 0 & $100\left(\mathrm{~K}^{+}\right)$ & 350 \\
\hline Beid04_no_surf_ions & 0.4 & 0 & $134\left(\mathrm{~K}^{+}\right)$ & 350 \\
\hline Beid05_no_surf_ions & 0.5 & 0 & $168\left(\mathrm{~K}^{+}\right)$ & 350 \\
\hline Beid06_no_surf_ions & 0.6 & 0 & $136\left(\mathrm{~K}^{+}\right) 32\left(\mathrm{Ca}^{2+}\right)$ & 350 \\
\hline Beid05_Mtm01_no_surf_ions & 0.6 & 0 & $136\left(\mathrm{~K}^{+}\right) 32\left(\mathrm{Ca}^{2+}\right)$ & 350 \\
\hline Beid04_Mtm02_no_surf_ions & 0.6 & 0 & $136\left(\mathrm{~K}^{+}\right) 32\left(\mathrm{Ca}^{2+}\right)$ & 350 \\
\hline Beid03_Mtm03_no_surf_ions & 0.6 & 0 & $136\left(\mathrm{~K}^{+}\right) 32\left(\mathrm{Ca}^{2+}\right)$ & 350 \\
\hline Beid02_Mtm04_no_surf_ions & 0.6 & 0 & $136\left(\mathrm{~K}^{+}\right) 32\left(\mathrm{Ca}^{2+}\right)$ & 350 \\
\hline Beid01_Mtm05_no_surf_ions & 0.6 & 0 & $136\left(\mathrm{~K}^{+}\right) 32\left(\mathrm{Ca}^{2+}\right)$ & 350 \\
\hline Mtm06_no_surf_ions & 0.6 & 0 & $136\left(\mathrm{~K}^{+}\right) 32\left(\mathrm{Ca}^{2+}\right)$ & 350 \\
\hline
\end{tabular}

${ }^{a}$ the structures with $700 \mathrm{H}_{2} \mathrm{O}$ molecules were not used in the contact angle calculations, but only in the calculations of the orientational distribution of $\mathrm{H}_{2} \mathrm{O}$ molecules depending on their distance from the surface. 


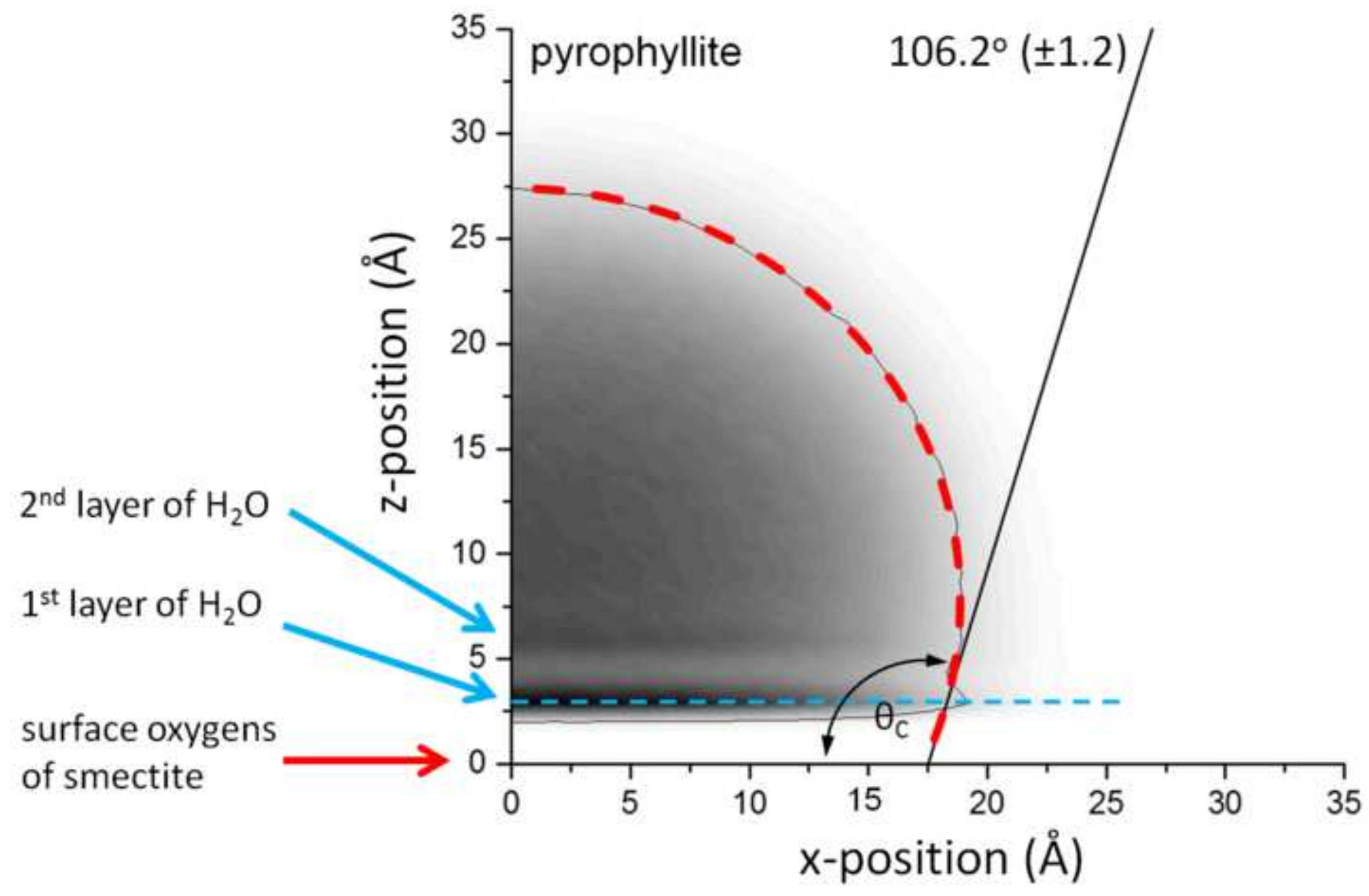


Click here to download high resolution image
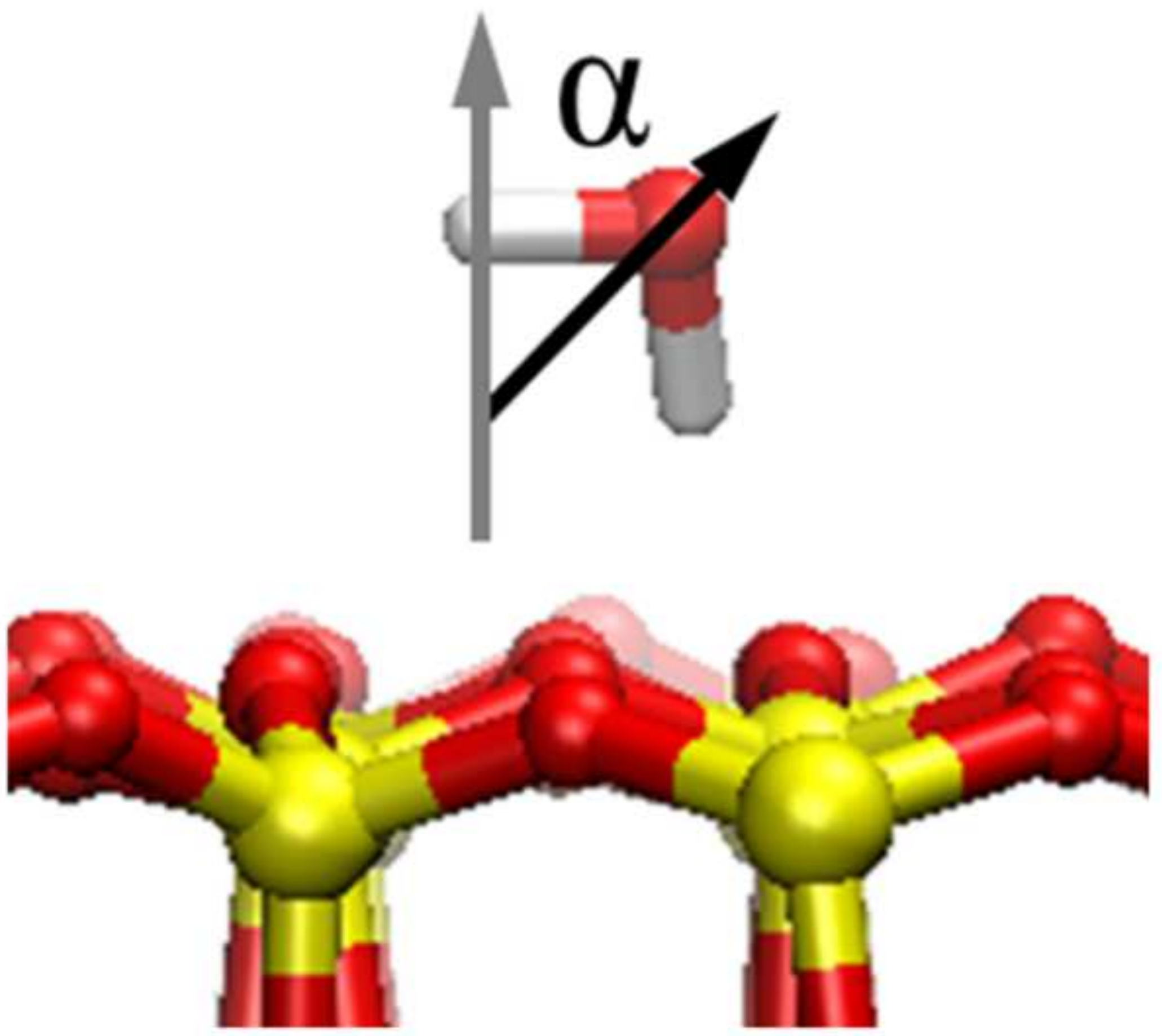

Figure 2 
Mtm03

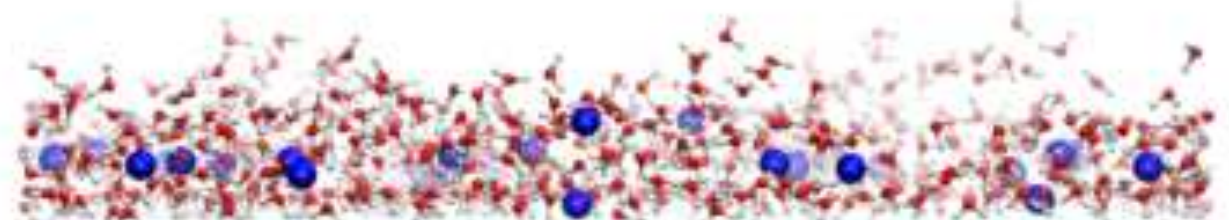

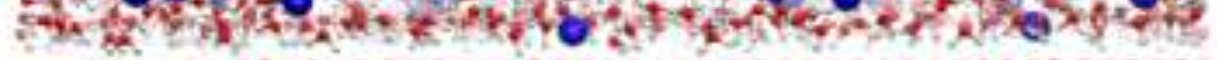

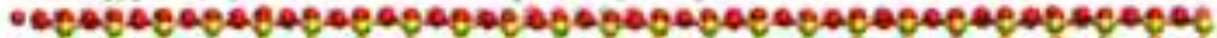

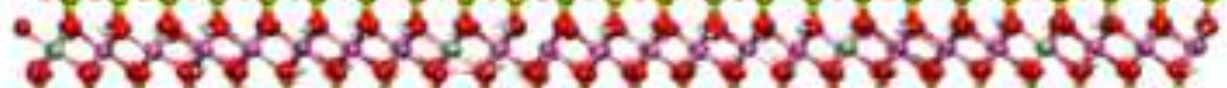

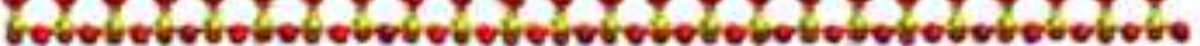

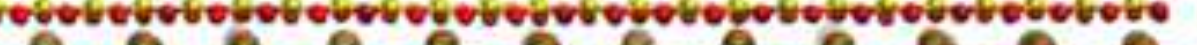

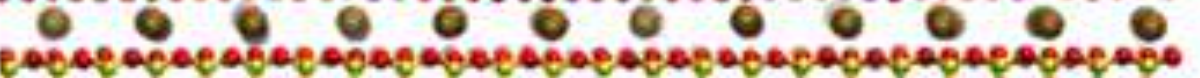

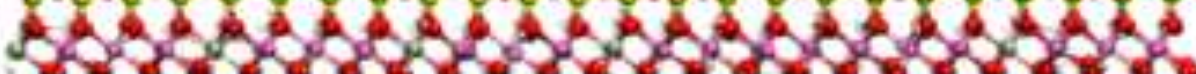

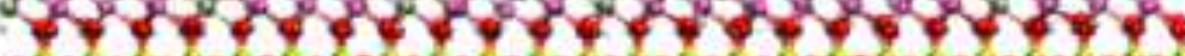

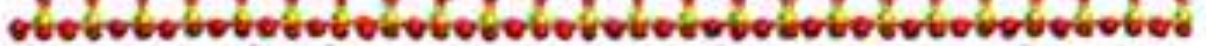

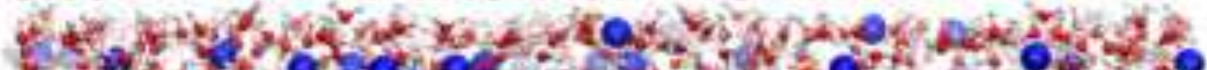

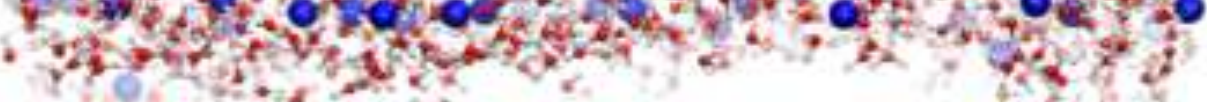

\section{Mtm03_no_surface_ions}

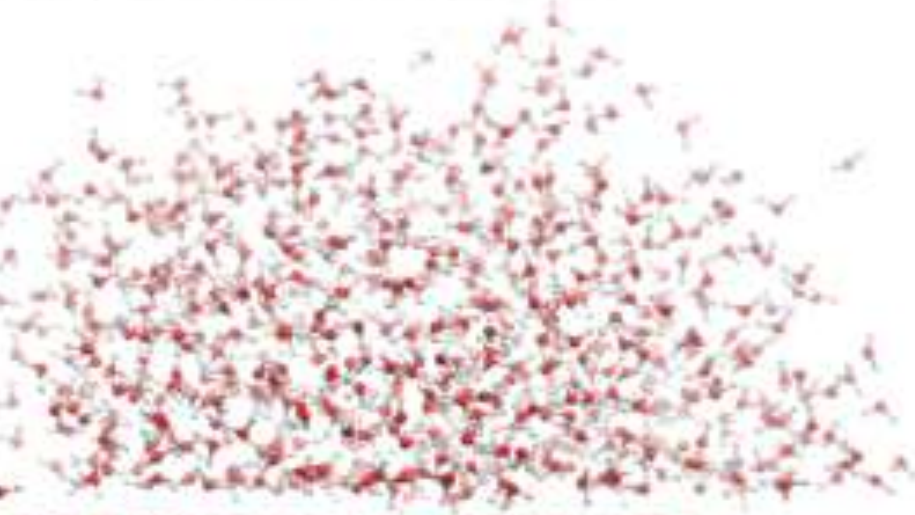

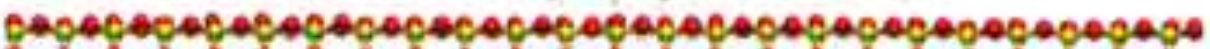

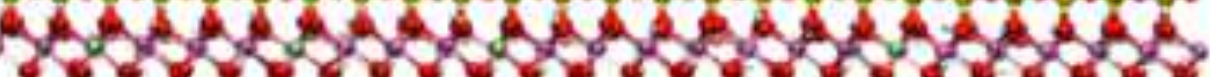

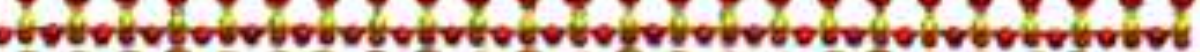

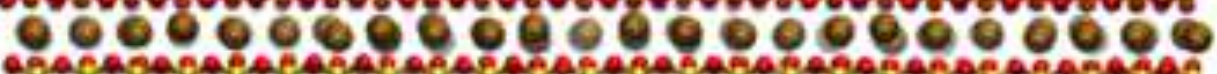

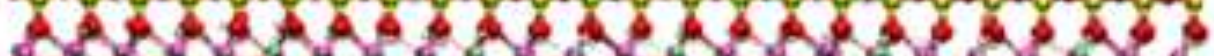
20.

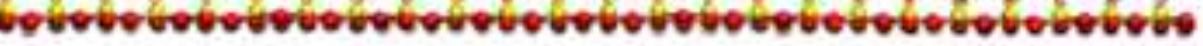

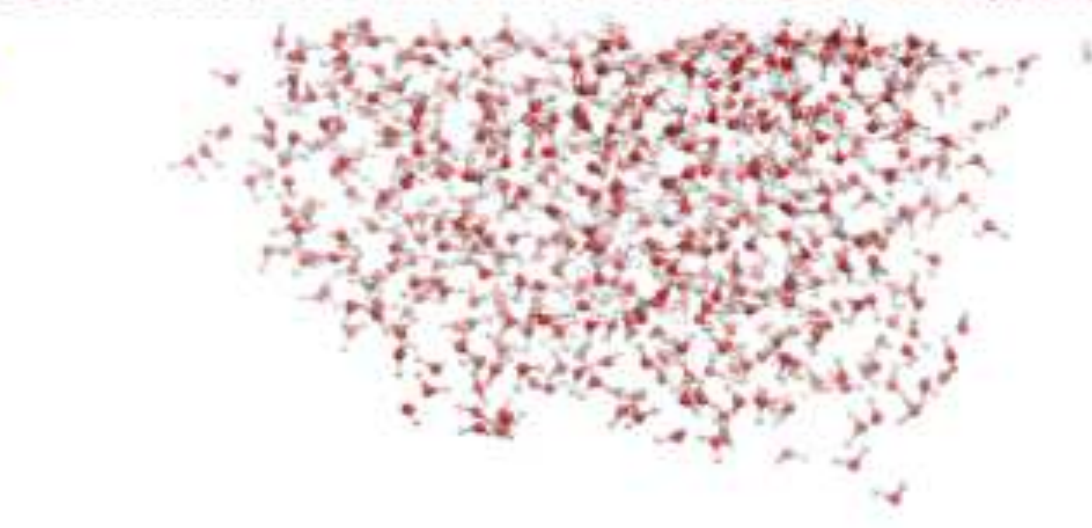




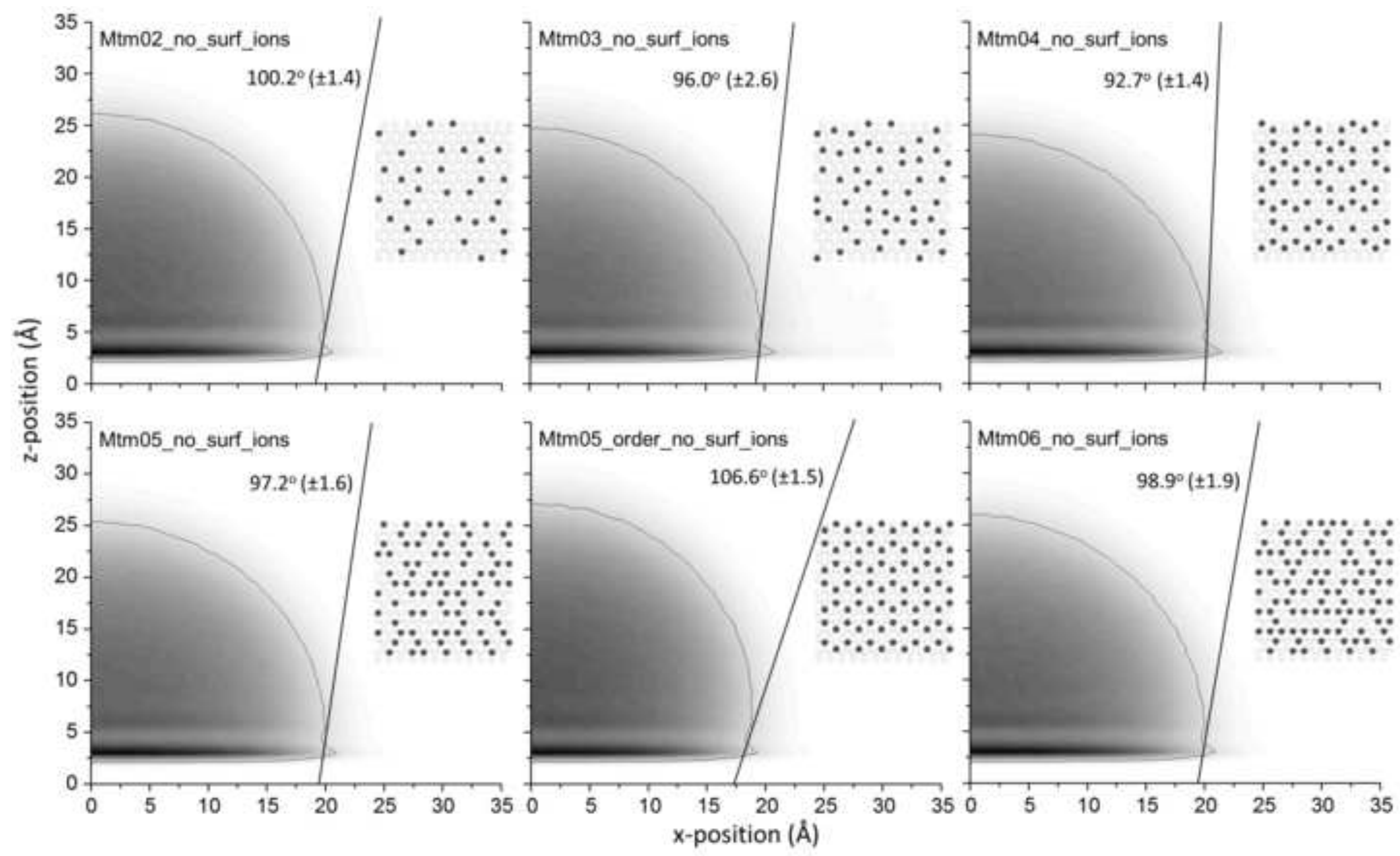


Click here to download high resolution image
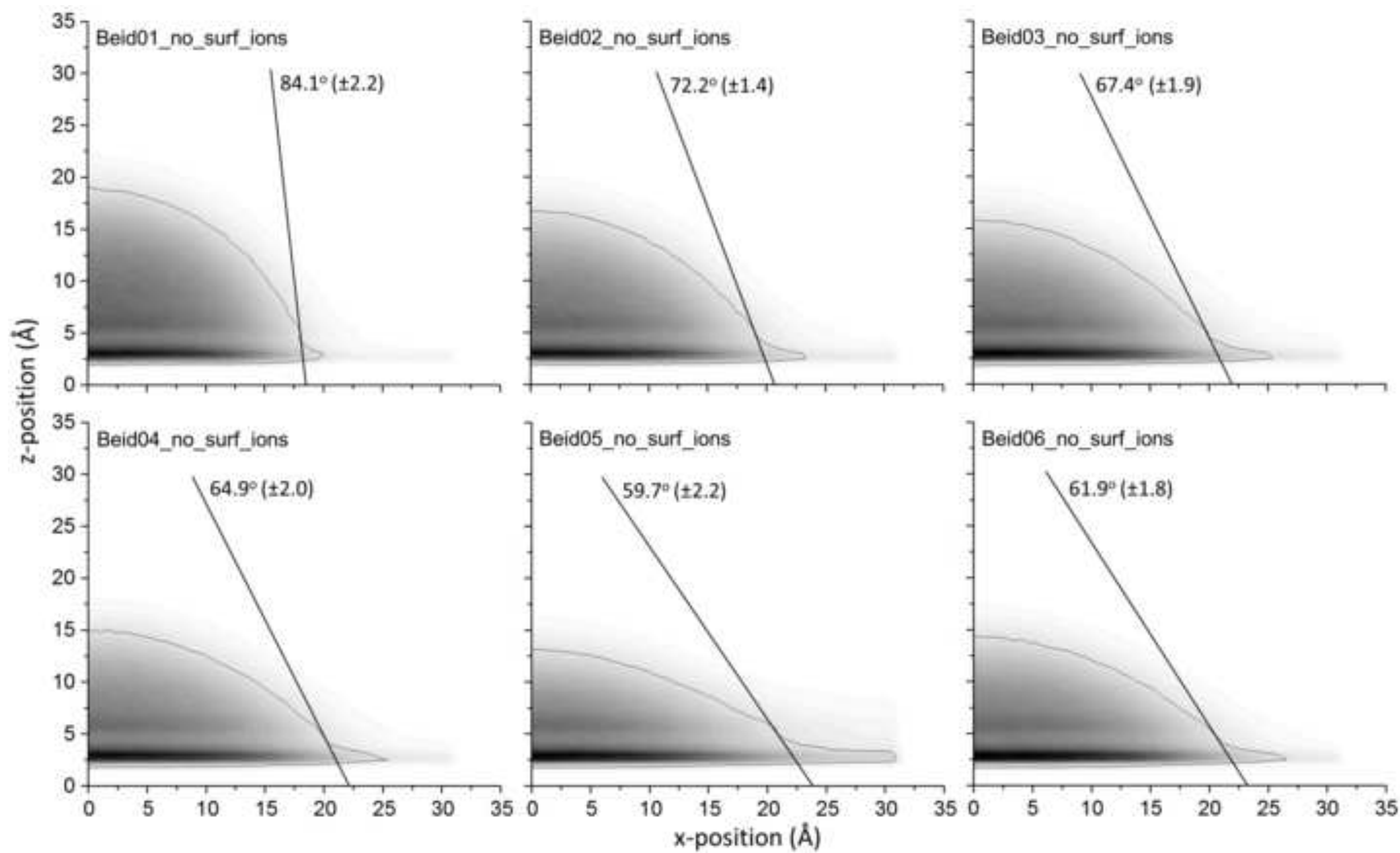
Click here to download high resolution image
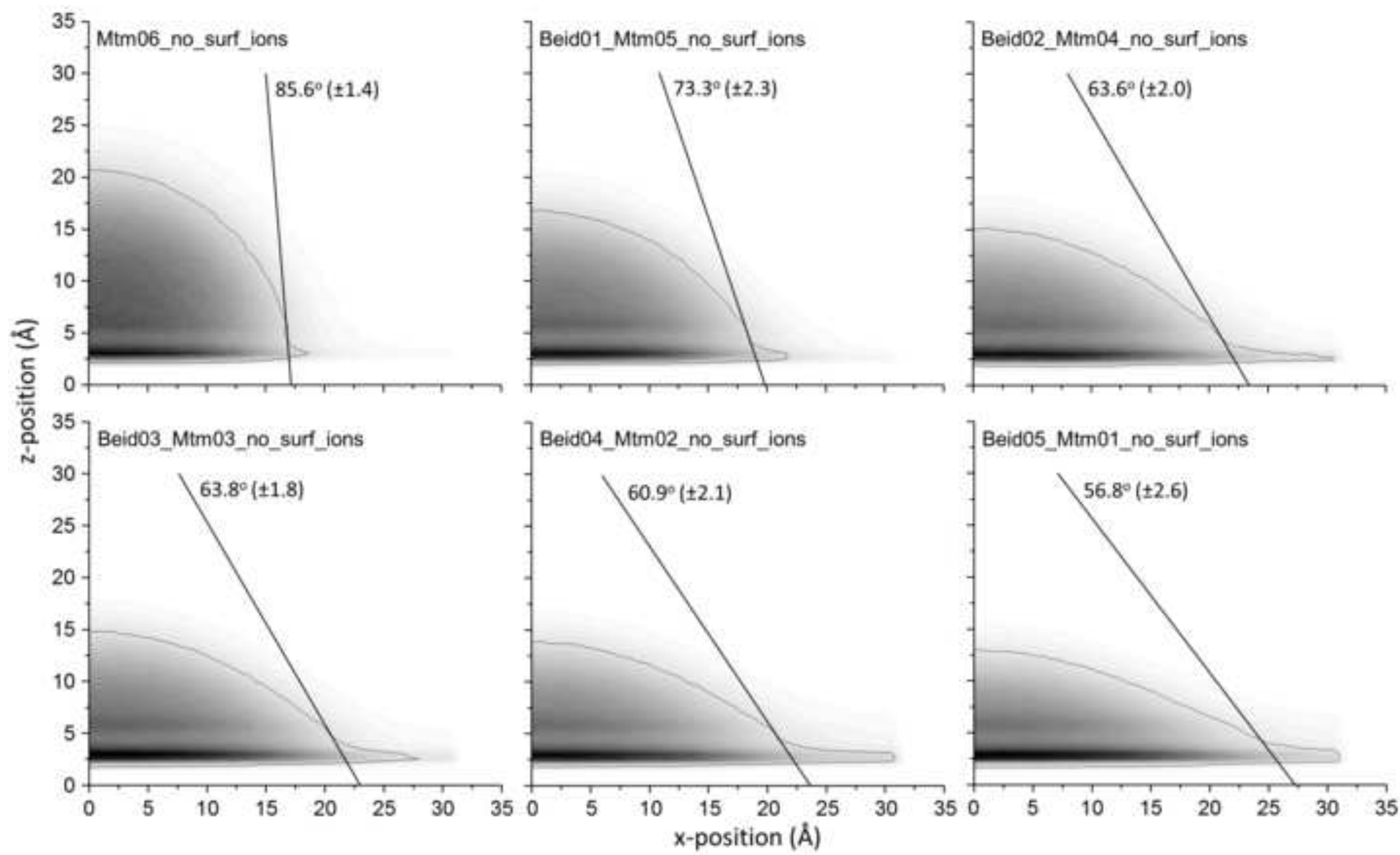
Click here to download high resolution image

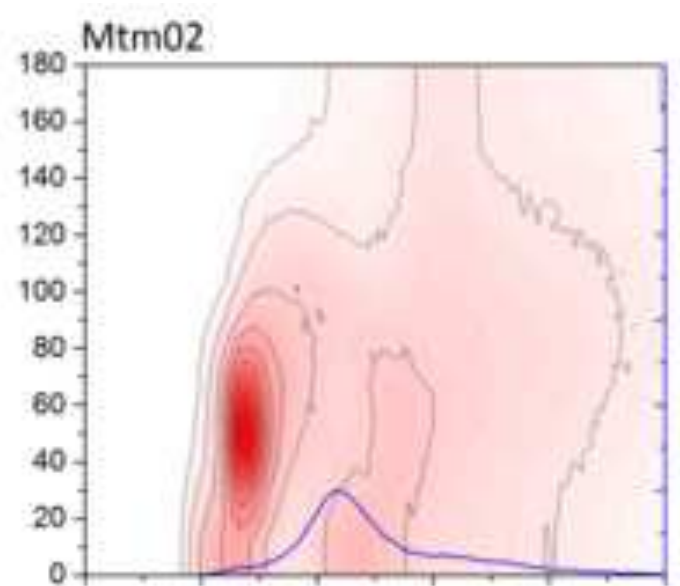

\section{Mtm03}
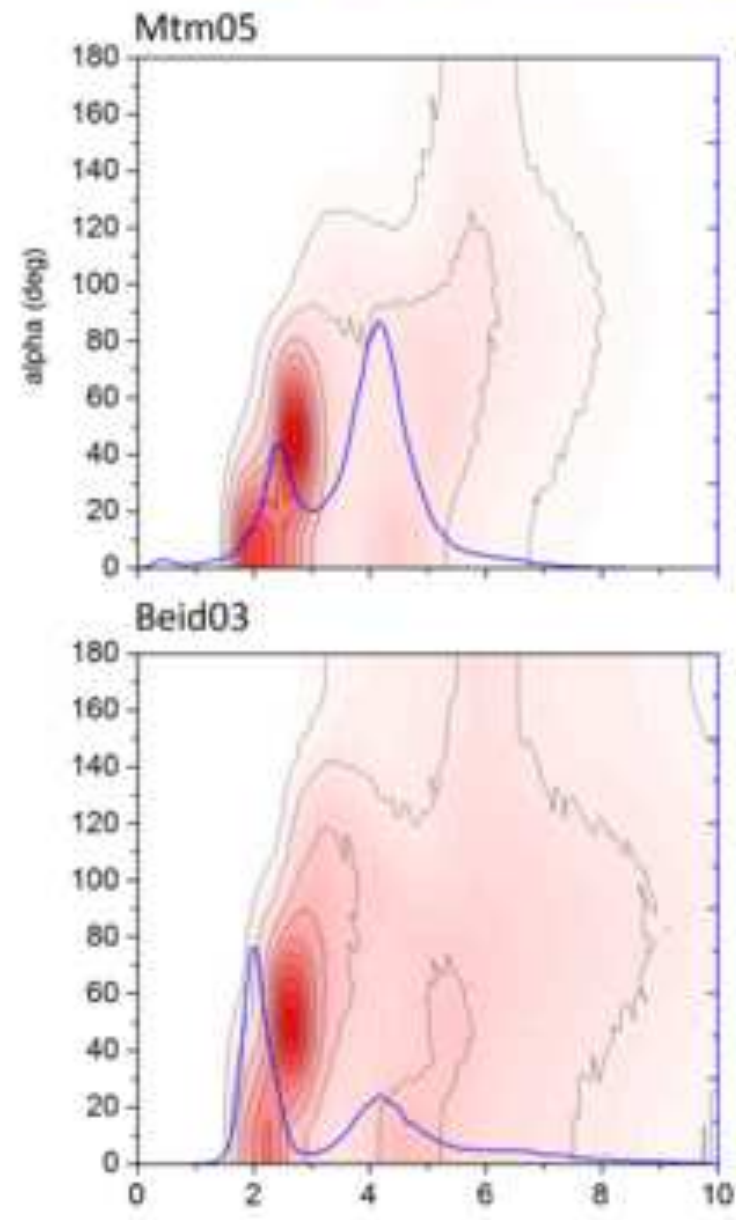

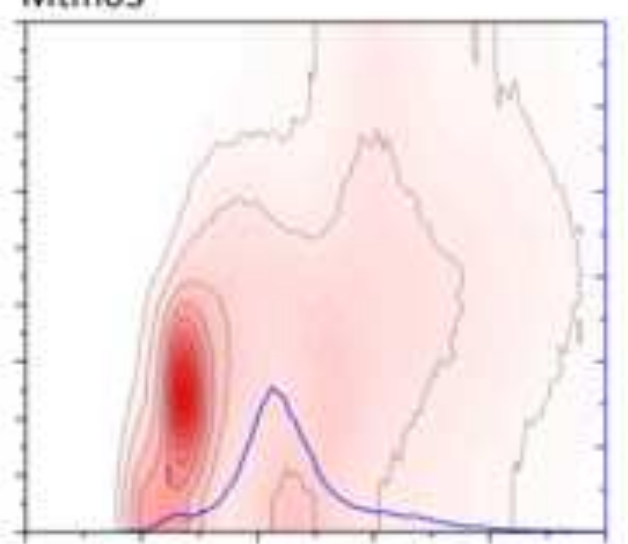

$\mathrm{Mtm04}$
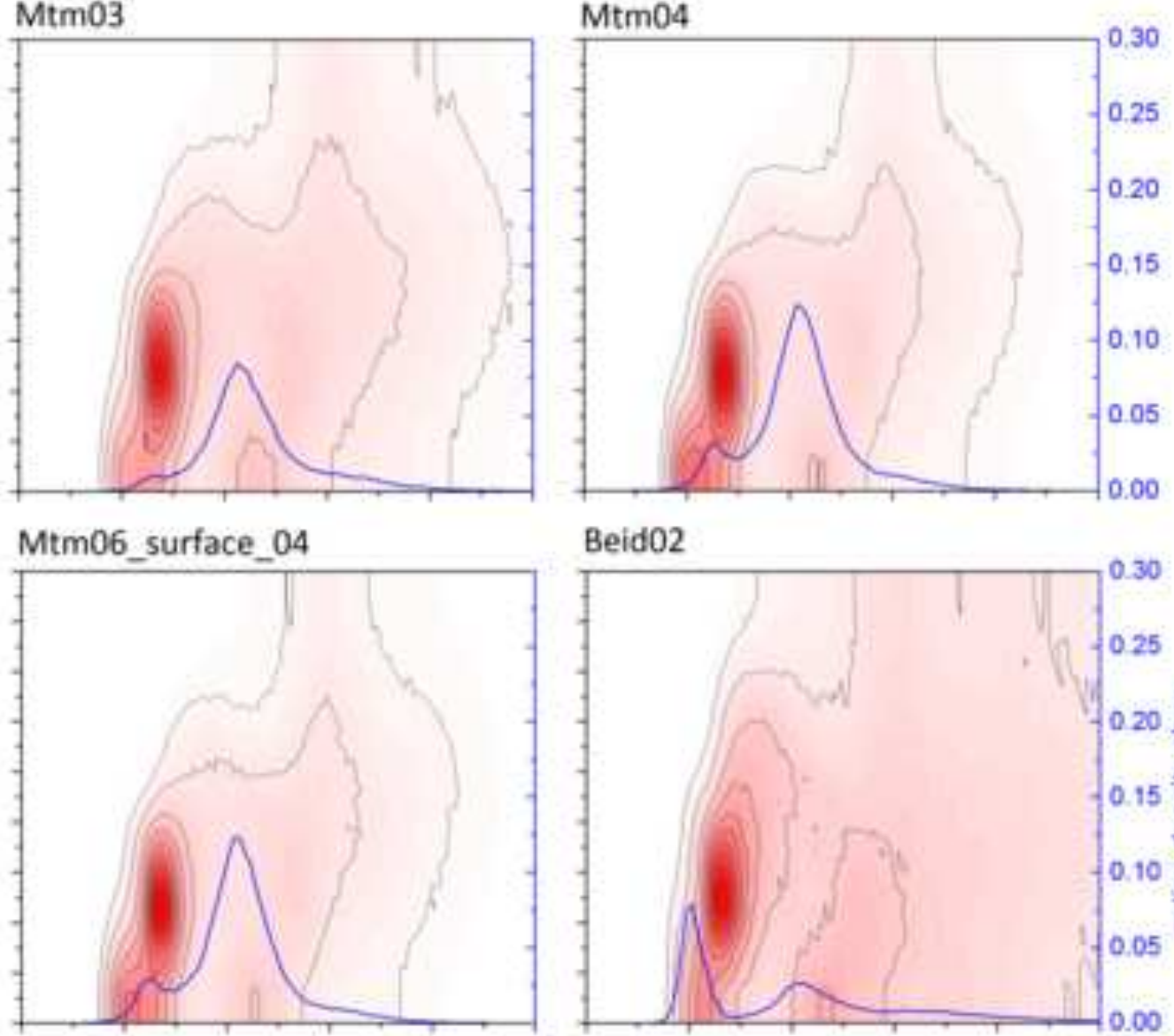

\section{Beid04}

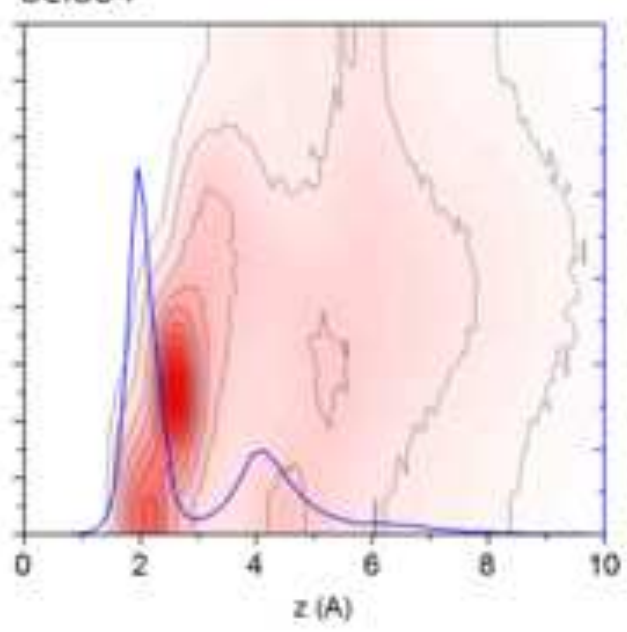

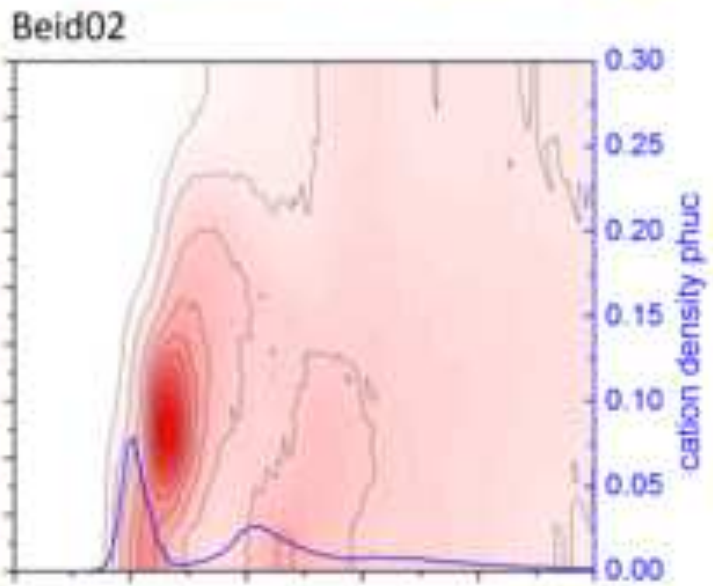

Beid05

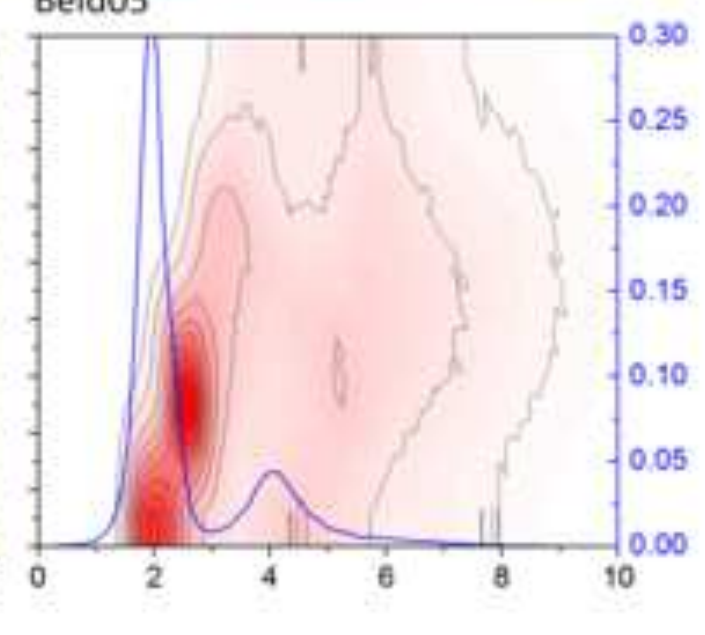



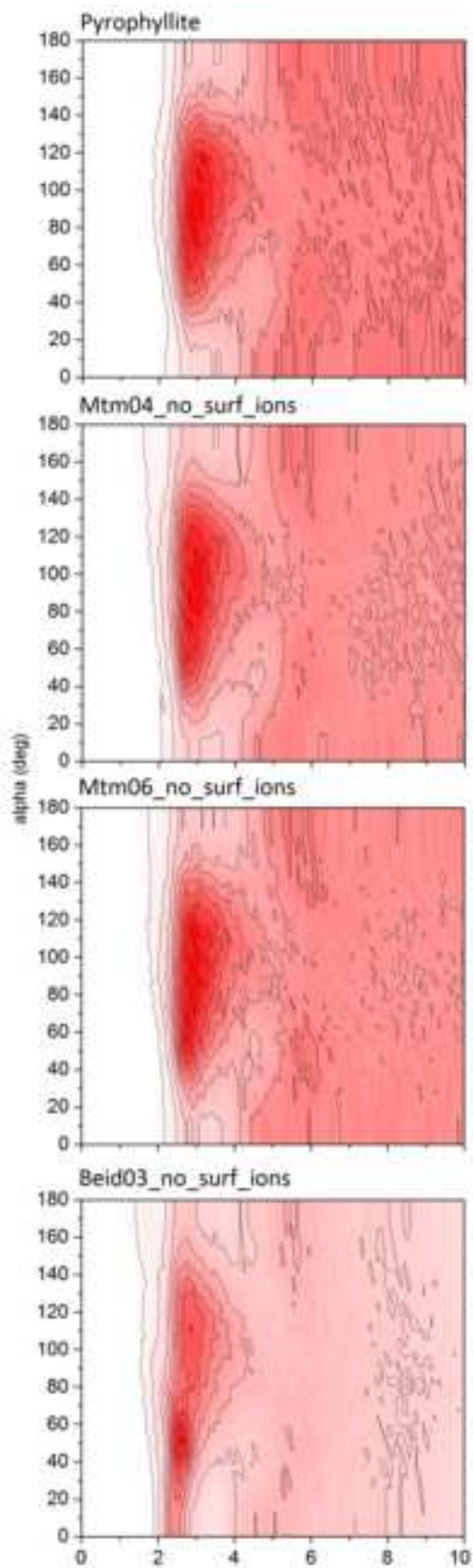

Mtm02_no_surf_ions

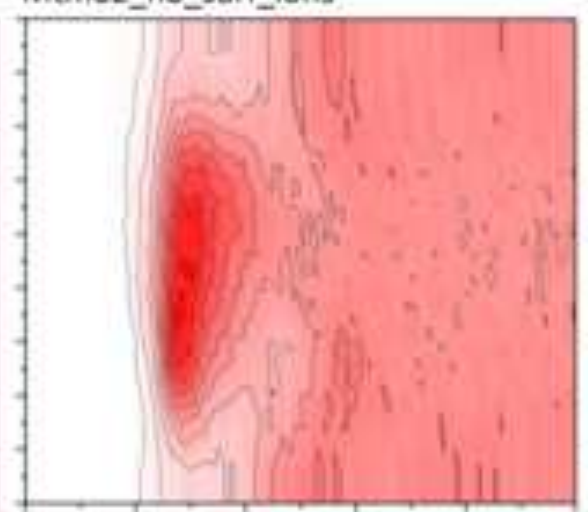

Mtm05_no_surf_ions

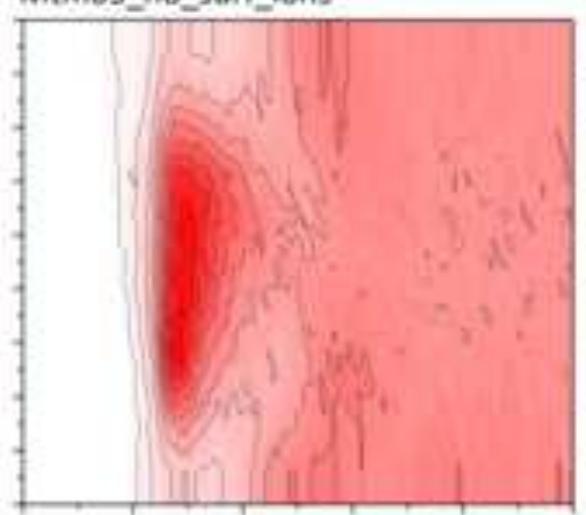

Beid01_no_surf_ions

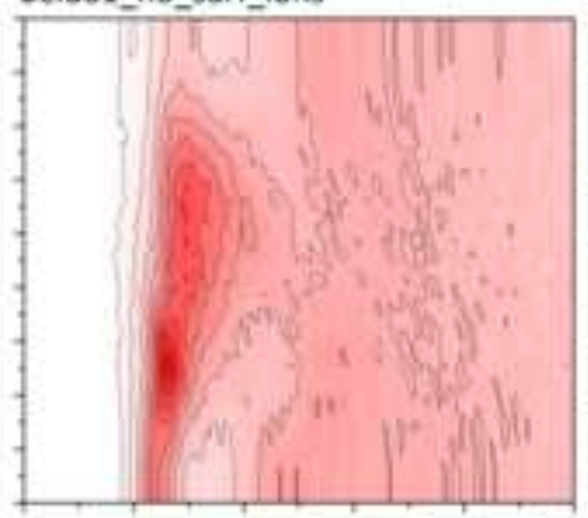

Beid04_no_surf_ions

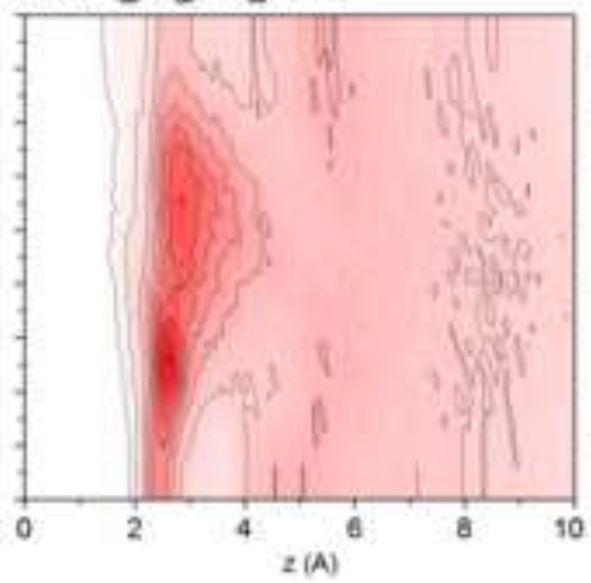

Mtm03 no_surf ions

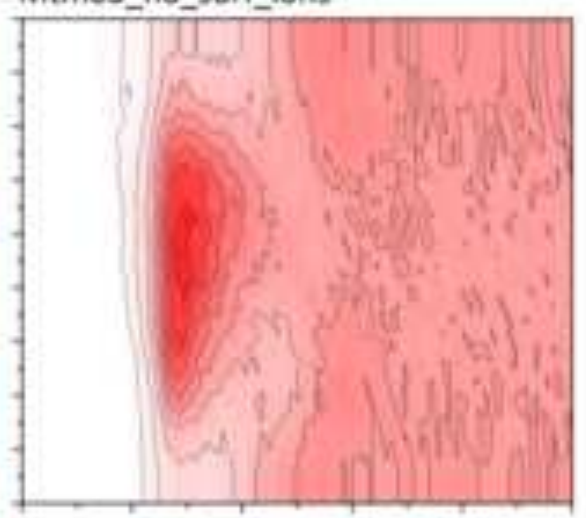

Mtm05_order_no_surf_ions

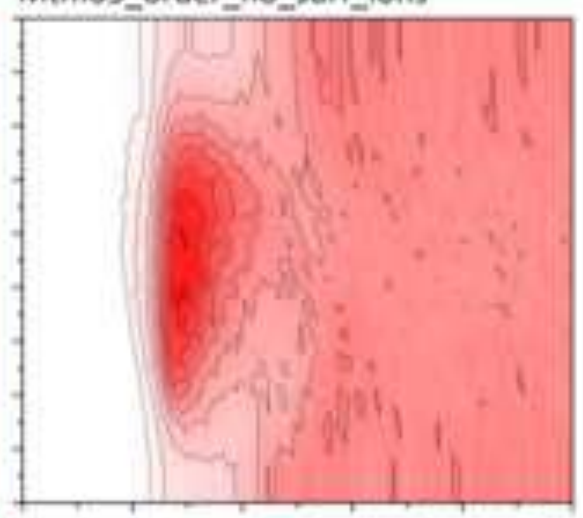

Beid02_no_surf_ions

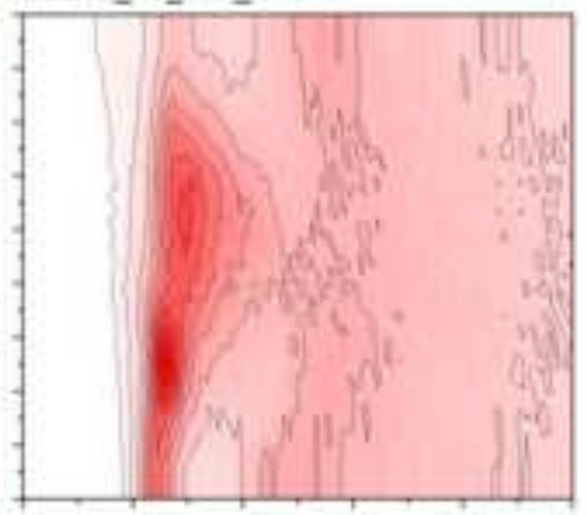

Beid05_no_surf_ions

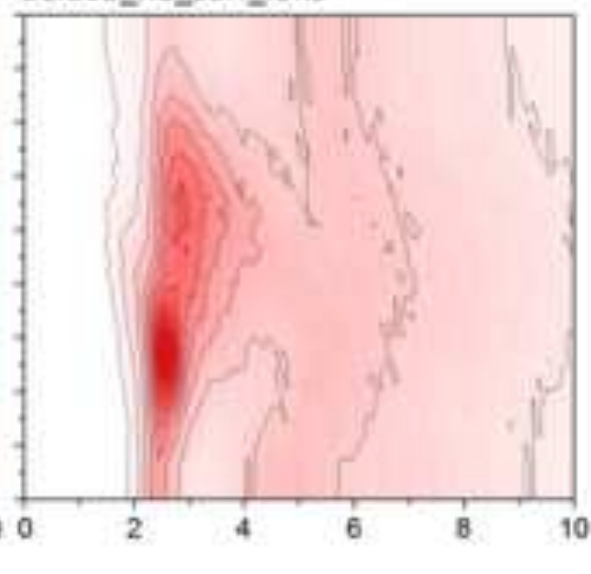




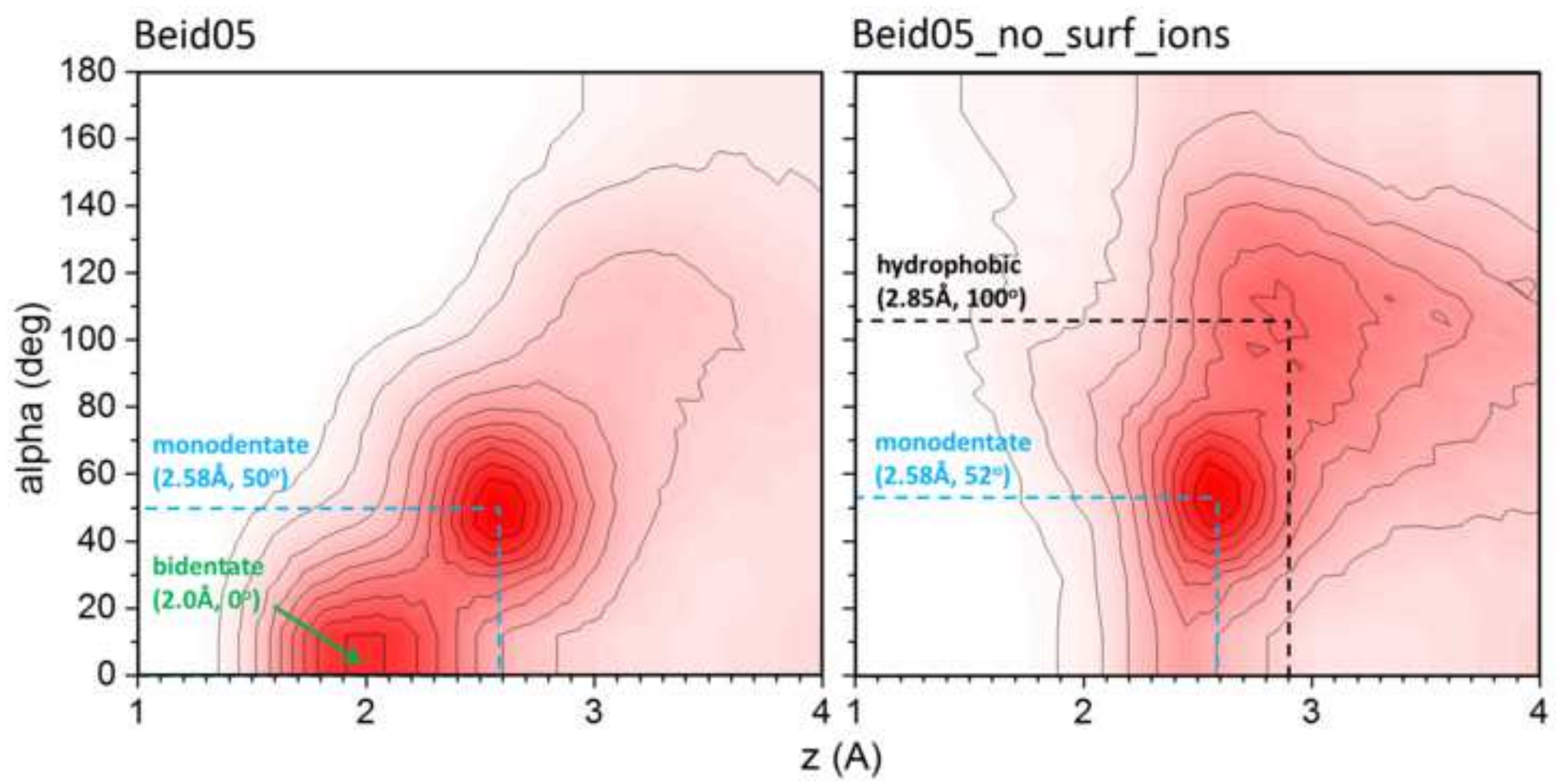


monodentate $(z=2.4-2.8, a=30-70)$

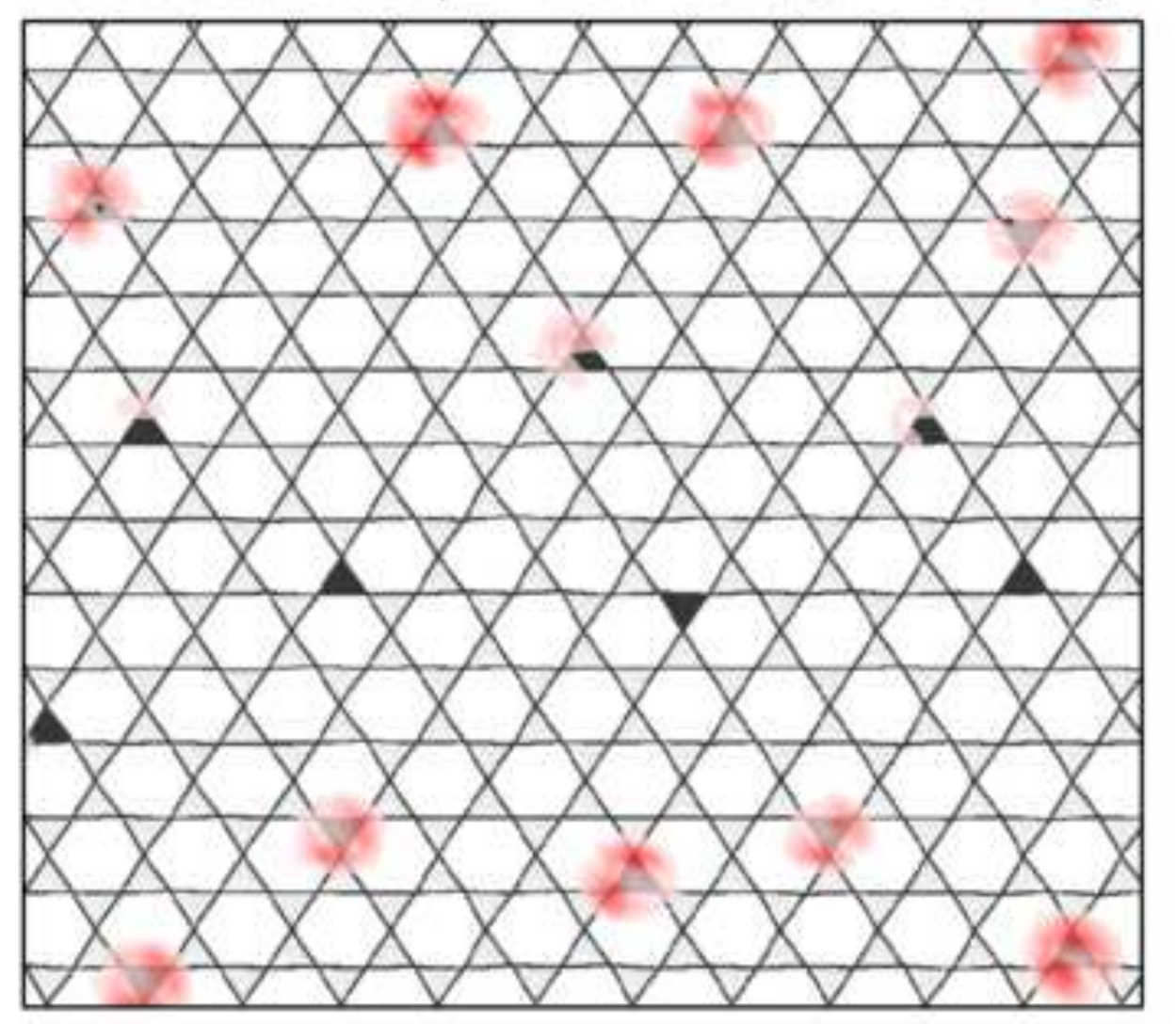

hydrophobic $(z=2.7-3.2, \alpha=80-140)$

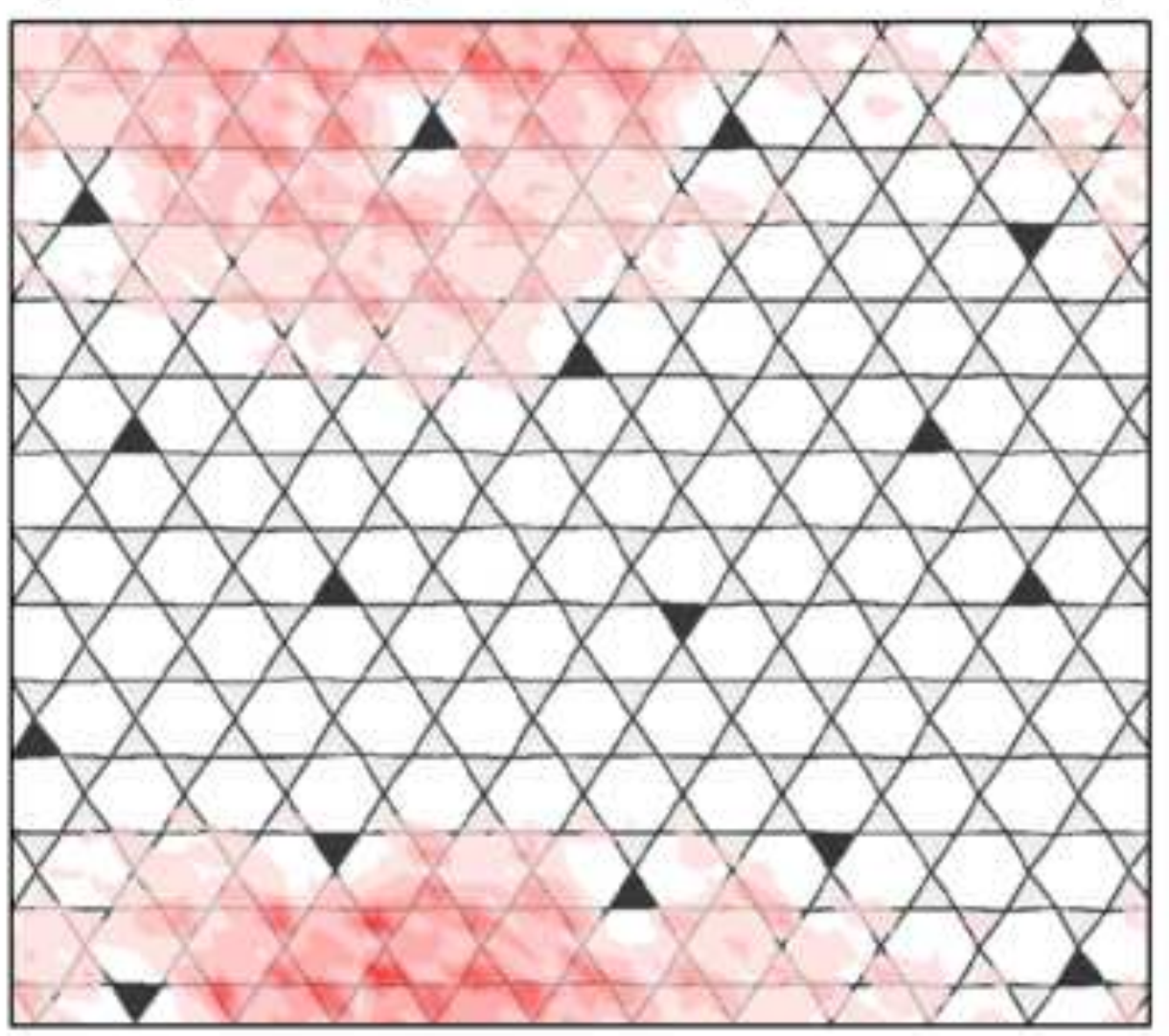




\title{
Supplementary materials for
}

“Intrinsic hydrophobicity of smectite basal surfaces quantitatively probed by molecular dynamics simulations”

\author{
Marek Szczerba ${ }^{1}$, Andrey G. Kalinichev ${ }^{2,3}$, Mariola Kowalik ${ }^{1}$ \\ ${ }^{1}$ Institute of Geological Sciences, Polish Academy of Sciences, Krakow, Poland \\ ${ }^{2}$ Laboratoire SUBATECH (UMR 6457 - Institut Mines-Télécom Atlantique, \\ Université de Nantes, CNRS/IN2P3) Nantes, France \\ ${ }^{3}$ National Research University Higher School of Economics, Moscow, Russian Federation
}

\section{Deformations of $\mathrm{SiO}_{4}$ tetrahedra in NPT simulations.}

In the NPT simulations with all atoms allowed to move, in some parts of the surface for the systems with all ions located in the interlayer between the 2:1 clay layers, some of $\mathrm{SiO}_{4}$ tetrahedra experienced significant deformations: Si-O basal distances remained the same, but the Si-O apical distance could become too long, apparently due to the quasi-ionic character of the ClayFF parametrization (Cygan et al., 2004). This lead to the mechanical deformation of tetrahedral sheets comparing to real crystallographic structures of the smectite 2:1 layers the Si-O basal distances are kept similar but the Si-O apical distance becomes too long (Figure S1). To prevent this from happening, the simulation structures were constructed based on the pre-optimized (in the NPT ensemble for $0.5 \mathrm{~ns}$, then in the $N V T$ for $0.5 \mathrm{~ns}$ ) pyrophyllite layer and then energy minimized anew. 


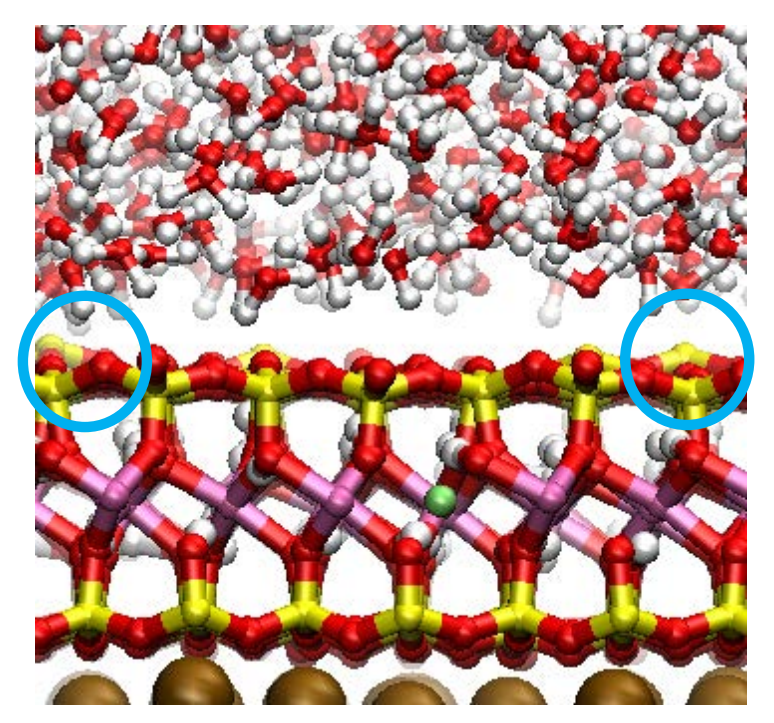

Figure S1. Deformation of $\mathrm{SiO}_{4}$ tetrahedra leading to exposure of some $\mathrm{Si}$ atoms above their crystallographic positions (blue circles). MD simulation run in in NPT-ensemble for the .Mtm05 structure.

\section{Check for equilibration of the shape of the droplet}
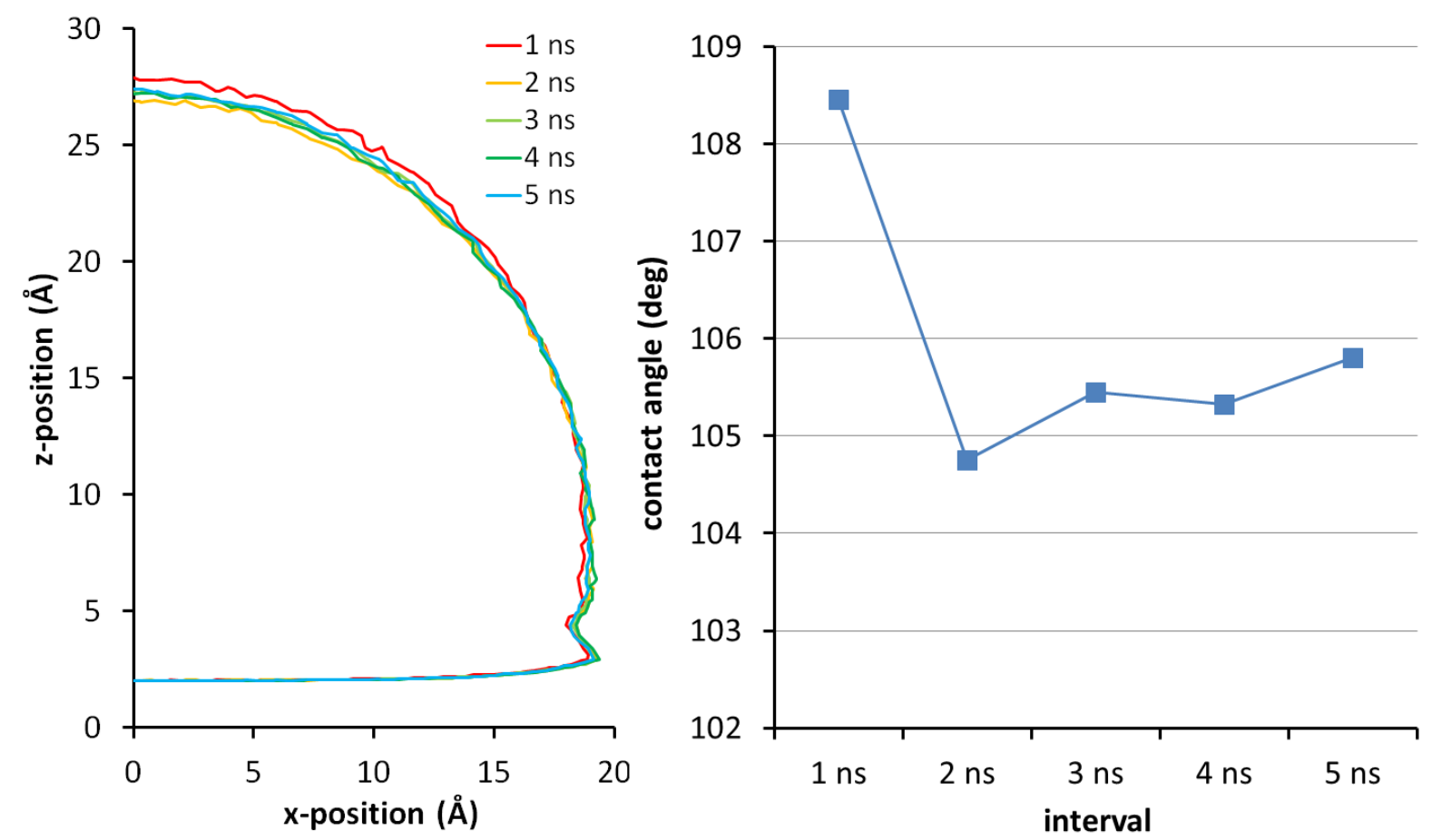

Figure S2. Enveloping curves calculated in $1 \mathrm{~ns}$ intervals for pyrophyllite along with corresponding contact angles. 


\section{Shape of the water film for smectites with $\mathrm{Na}^{+}$ions on the surface.}

Irregularity of monotonous, flat water film is correlated with the number of sodium ions on the surface: the more $\mathrm{Na}^{+}$ions, the less rugged is the boundary between the water film and the surrounding "vapour phase” (Figs. S2-S5).

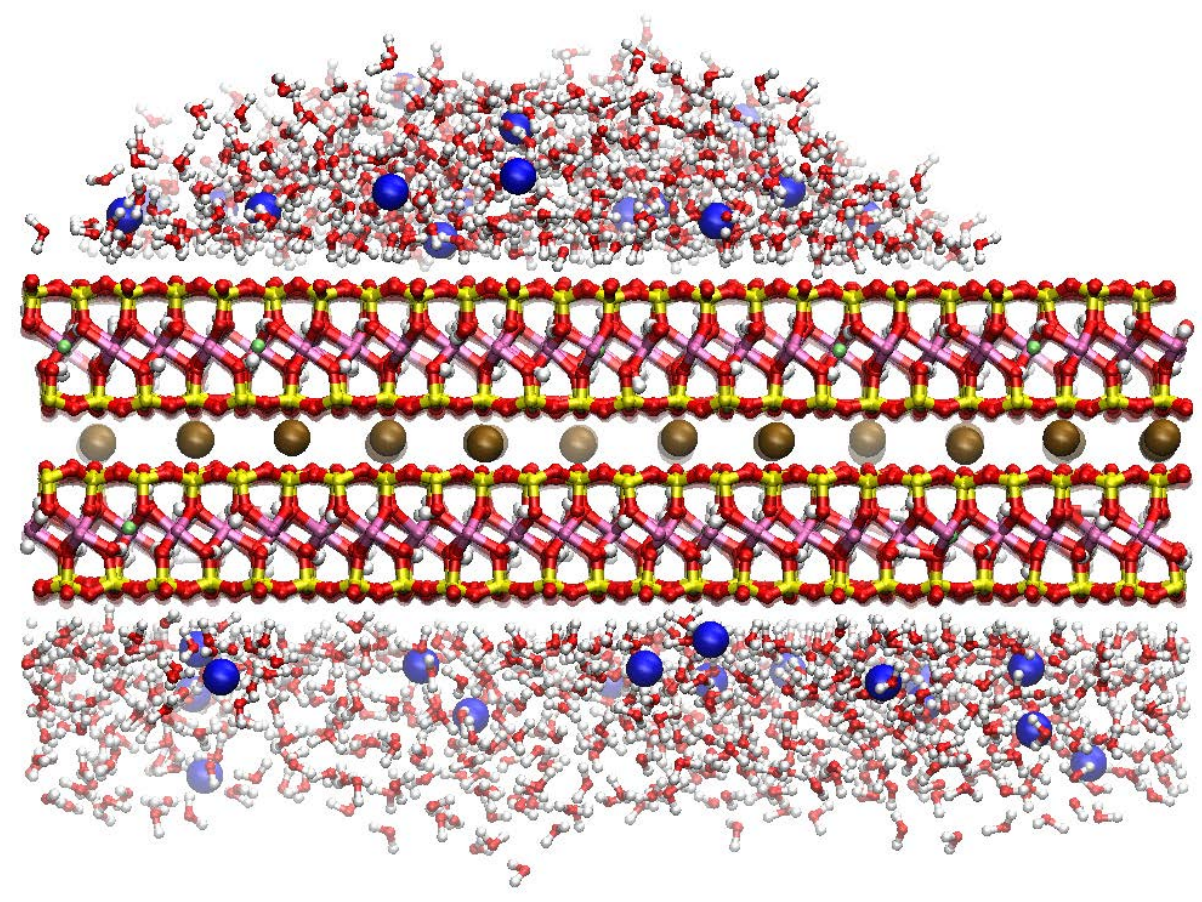

Figure S2. Final snapshot of simulation for Mtm02. 


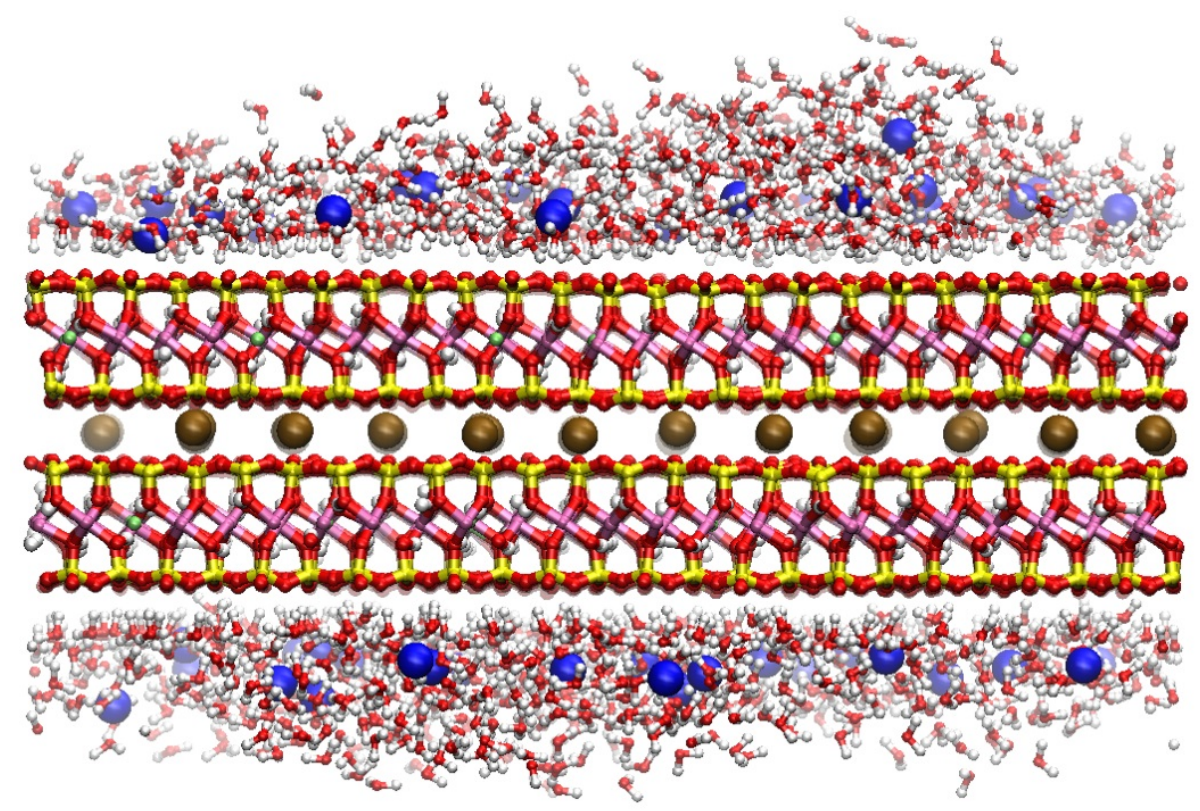

Figure S3. Final snapshot of simulation for Mtm03.

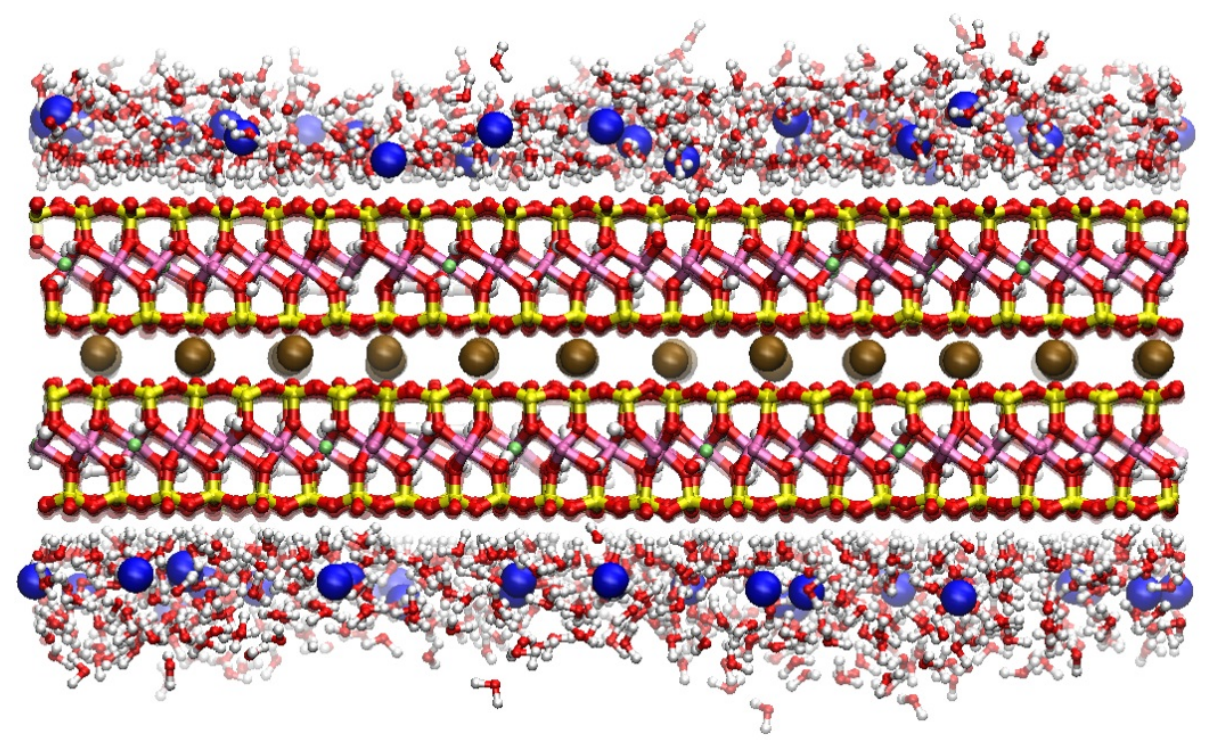

Figure S4. Final snapshot of simulation for Mtm04. 


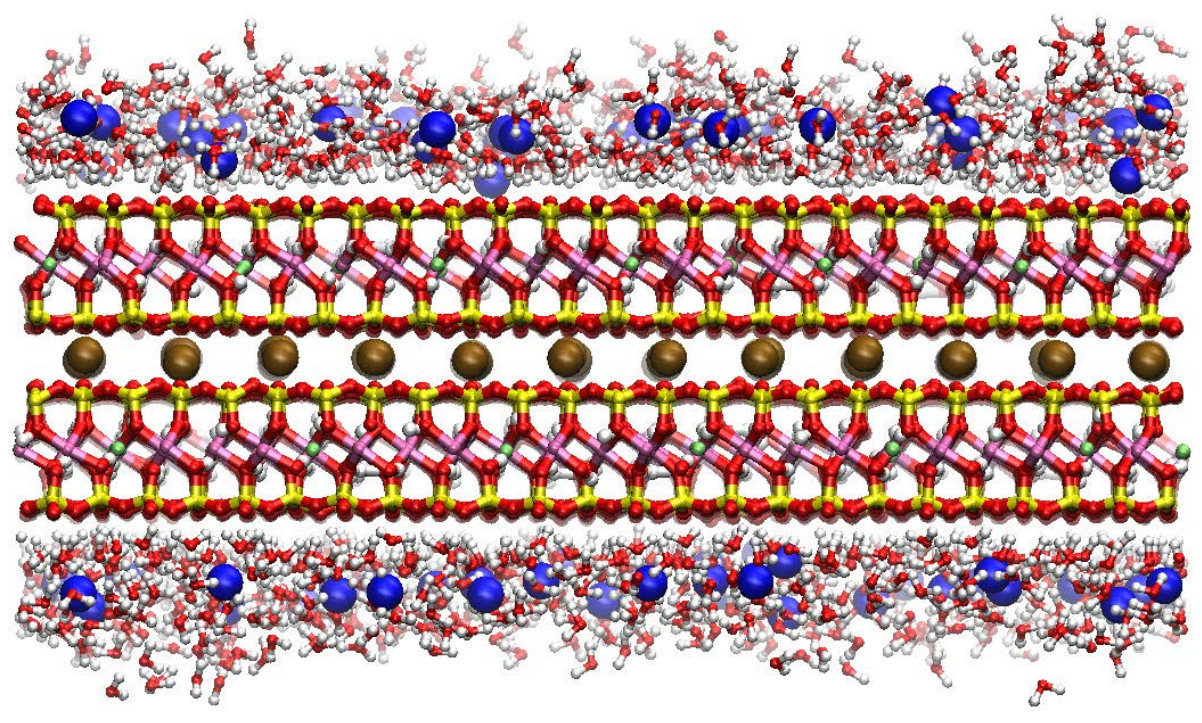

Figure S5. Final snapshot of simulation for Mtm05_order. 